\title{
First-price equilibrium and revenue equivalence in a sequential procurement auction model
}

\author{
J. Philipp Reiß · Jens Robert Schöndube
}

Received: 20 December 2006 / Accepted: 13 November 2008 / Published online: 10 December 2008 (C) The Author(s) 2008. This article is published with open access at Springerlink.com

\begin{abstract}
We analyze first-price equilibrium bidding behavior of capacityconstrained firms in a sequence of two procurement auctions. In the model, firms with a cost advantage in completing the project auctioned off at the end of the sequence may enter the unfavored first auction hoping to lose it. Equilibrium bidding in both auctions deviates from the standard Symmetric Independent Private Value auction model due to opportunity costs of bidding created by possibly employed capacity. For this sequential auction model with non-identical objects, we show that revenue equivalence applies.
\end{abstract}

Keywords Sequential first-price auctions - Revenue equivalence $\cdot$ Endogenous outside options · Procurement auction · Capacity constraints

JEL Classification $\quad$ C72 $\cdot$ D $44 \cdot$ L5 1

\begin{abstract}
We thank Werner Güth and Ulf Schiller for helpful comments and stimulating discussions. The paper greatly benefited from very helpful comments of the associate editor and two reviewers. We gratefully acknowledge comments from Jeannette Brosig, Veronika Grimm, Alfred Luhmer, Barbara Schöndube-Pirchegger, Gerhard Schwödiauer, and audiences at Erfurt, Frankfurt, Fribourg, Heidelberg, Leuven, Maastricht, Magdeburg, Marseille, Mannheim, Munich, and Swansea.
\end{abstract}

J. P. Reiß $(\varangle)$

Economics Department, Maastricht University, 6200 MD Maastricht, The Netherlands

e-mail: p.reiss@algec.unimaas.nl

J. R. Schöndube

Faculty of Economics and Management, University of Magdeburg,

39016 Magdeburg, Germany

e-mail: jens.schoendube@ww.uni-magdeburg.de 


\section{Introduction}

This paper studies first-price equilibrium bidding behavior in a sequential procurement auction model with capacity-constrained firms. Usually procurers differ across regions, firms, and institutions and set independently of each other different auction dates implying a sequence of auctions. Often projects to be auctioned off are similar and offered for execution during the same window of time. Although the sequential nature of procurement auctions is prevalent, many theoretical studies implicitly abstract it away by focussing on a single procurement auction in isolation (e.g., Holt 1980; Riordan and Sappington 1987; McAfee and McMillan 1987b; Dasgupta and Spulber 1989; Celentani and Ganuza 2002).

In sequential procurement auction theory, it is common to assume that any bidding firm has unlimited capacity to execute all sequentially offered projects, see, e.g., Luton and McAfee (1986). ${ }^{1}$ However, recent empirical studies on sequential procurement auctions point to the relevance of capacity constraints. De Silva et al. (2002, 2003) find that bids are positively correlated with employed capacity. Jofre-Bonet and Pesendorfer $(2000,2003)$ report that a firm which did not win a highway procurement contract earlier in a sequence of auctions is twice as likely to enter a subsequent auction than a firm which already won a (large) contract. This evidence suggests that firms are aware of their opportunity costs of bidding created by employed capacity and might be choosy if facing an auction sequence of non-identical procurement contracts.

We consider a sequence of procurement auctions in the first-price sealed-bid design where projects are stochastically equivalent and bidding firms are capacityconstrained. Since a potential bidding firm finds itself restricted to execution of a subset of sequentially offered heterogenous projects, it must decide which procurement auctions to enter entailing a selection of projects it wishes to possibly end up with.

For a procurement sequence of identical projects, the analysis of Weber (1983) suggests that equilibrium expected payments of winning bidders coincide and, hence, any firm may want to begin bidding at the start of the sequence. If, however, firms prefer to execute one project to another due to different project completion costs, it is a priori not clear if a firm with more favorable completion costs for projects to be auctioned later in the sequence submit bids for projects auctioned earlier.

This paper studies this kind of entry decision and analyzes how firms refine their bidding strategies with opportunity costs of early bid submission. Our main findings are that the entry decision depends on relative project completion cost values and equilibrium bidding in both auction stages deviates from the standard Symmetric Independent Private Value auction model (SIPV) and its sequential formulation with homogenous goods and single-unit demand. Firms with lower completion costs for the first project auctioned off always submit bids while firms with lower completion costs for the project subsequently auctioned off only participate if their opportunity costs are not too large. Each firm entering the first auction includes its option value of the second project in its bid for the first project. Moreover, we derive revenue and payoff equivalence for the sequential model with non-identical projects.

\footnotetext{
${ }^{1}$ Exceptions include Elmaghraby (2003) and Gale et al. (2000) where in the latter the cost function can be chosen to effectively allow for capacity constraints.
} 
An experimental investigation of our sequential first-price auction model, see Brosig and Reiß (2007), finds that the bidding deviations from the standard SIPV model predicted by our model are, indeed, observed in the laboratory. This finding emphasizes that opportunity costs of early bid submissions are understood by bidders and form a crucial determinant of bidding behavior.

In the remainder of this section we relate our paper to the relevant literature on sequential auctions. Section 2 introduces our model and its symmetric equilibrium. In Sect. 3, we derive payoff and revenue equivalence. Section 4 investigates differences between the static SIPV model and the sequential model. In particular, we illustrate how the option value of subsequent contract opportunities affects bidding decisions of firms. In Sect. 5 we extend the model to allow for reserve prices and weak capacity constraints, finally Sect. 6 concludes.

\subsection{Ties to the literature}

In recent years the literature has devoted increasing attention to sequential auctions (predominately in the non-procurement context). Inspired by Ashenfelter's (1989) observation of declining prices in wine auctions where identical cases were sold one after the other, part of the literature aimed at deriving a theoretical explanation for the violation of the "law of one price" that the has been dubbed "declining price anomaly" ever since. ${ }^{2}$ For example McAfee and Vincent (1993) explain it by risk averse bidders, Black and De Meza (1992) show that a winner's option to buy further objects at the same price leads to decreasing prices and Bernhardt and Scoones (1994) and Engelbrecht-Wiggans (1994) derive a falling price trend by assuming stochastically equivalent objects. While recent work suggests that strategic behavior in an auction sequence is a driving force for this anomaly, Deltas and Kosmopoulou (2004) demonstrate that part of the overall effect cannot be explained by strategic considerations.

\subsubsection{Price trends and competition}

Decreasing equilibrium prices in sequential auctions often come along with a reduced degree of competition. Von der Fehr (1994) considers a sequence of two English auctions with participation costs. As the first auction provides a ranking of bidders' valuations, bidders who have no chance to win the second auction do not enter this auction if participation is costly. Gale and Hausch (1994) employ a sequence of two objects in the right-to-choose format with two bidders having unit demand. In equilibrium there is no competition in the second auction such that the loser of the first auction wins it for a price of zero (the seller's reserve). Jeitschko (1999) considers a sequence of two auctions where the second one only occurs with some exogenous probability. He finds that the uncertain prospect of the second auction redirects competitive pressure to the first auction at the expense of competition in the second auction.

\footnotetext{
2 It should be noted that increasing price paths have been derived in some papers, e.g., Black and De Meza (1992). In Engelbrecht-Wiggans (1994) depending on the distributional assumptions expected equilibrium prices may increase or decrease. In Menezes and Monteiro (2003) the price trend depends on whether objects have positive or negative synergies.
} 
Branco (1997) assumes complementarities between objects in a sequence of two auctions: Bidding behavior in the first auction stage is more aggressive than in the second stage as there is only one bidder remaining after the first auction who can win the bundle of objects. ${ }^{3}$ Engelbrecht-Wiggans (1994) analyzes a sequence of auctions with stochastically equivalent objects and unit demand bidders. On the one hand there is a declining prices effect as the number of bidders shrinks as the course progresses in the auction sequence. On the other hand the number of remaining chances to win the object decreases over the sequence of auctions facilitating more aggressive bidding over time. While in Weber's (1983) analysis with identical objects these two effects neutralize each other with stochastically equivalent objects equilibrium prices can decline.

We do not focus on price trends in this paper, though, endogenous competition is one major concern. Compared to the models above in this paper the degree of competition in the second auction depends on endogenous entry in the first auction. In equilibrium, depending on the option value of participation in the second auction, no bidder may enter the first auction. However, even if there is competition in the second auction we demonstrate that bidding behavior does not coincide with equilibrium bidding in the static SIPV model. The reason is that all bidders on the second auction stage receive a signal on completion costs of their opponents. Unlike with second price auctions studied elsewhere, first price equilibrium bidding is affected by updates of bidders' beliefs about their competitors.

\subsubsection{Option value and endogenous entry}

A number of models analyzing the influence of the option value of future auctions on bidding strategies assumes-like this paper-capacity constrained (unit demand) bidders. Bernhardt and Scoones (1994), Engelbrecht-Wiggans (1994), and Von der Fehr and Riis (1998) assume that each bidder learns his valuation for a specific object immediately before the time of sale whereas in our model costs for both objects are realized at the beginning of the first auction. Letting bidders learn the costs for all objects at the beginning of the sequence considerably affects strategic participation in the first period.

Zeithammer (2007) employs an overlapping generations model to analyze the interaction of buyers' bid shading strategies and the seller's selling decision. Anticipating future auctions bidders have an incentive to shade their bids in the current auction but at the same time the seller- anticipating bid shading- will learn form observed prices on actual demand. Zeithammer shows that in equilibrium bid shading survives but it is self-regulating in the sense that it vanishes before the market breaks down.

Consistent with the above finding that option values lead to less aggressive bidding behavior we show in the procurement context how first auction equilibrium bids are increasing in the option value resulting from the second auction. This result does not only hold in case of strong capacity constraints (in the sense that each firm can at most

3 Menezes and Monteiro (2003) show that with negative synergies prices are increasing. 
execute one contract) but it carries over to the case that firms can purchase additional capacity to execute a second project conditional on winning the first one.

While accounting for the option value is ubiquitous there are few papers that explicitly discuss endogenous participation. As mentioned above a participation cost may induce bidders not to participate in an auction if the chance to win the auction is rather low (Von der Fehr 1994). In Caillaud and Mezetti (2004) the seller cannot ex ante commit to a reserve for the second auction. In equilibrium bidders may decide not to participate in the first auction to avoid a high second period reservation price. In analyzing endogenous participation in terms of the option value of future auction with capacity constrained bidders our model is closely related to Gale and Hausch (1994). They discuss entry behavior in sequential auctions in the second-price format. In a two bidders-two auctions model with unit demand Gale and Hausch demonstrate that bottom fishing may show up. A bidder with a preference for the second project may submit a low bid in the first auction: If he loses he wins the preferred object, and if the competitor also prefers the second object he may win the first object at a low price. Gale and Hausch also show that in equilibrium both bidders might decide to skip the first auction. ${ }^{4}$ In our paper we emphasize the relation between the endogenous option value in the first auction and non-entry behavior. We also show that this relation does not depend on strong (unit demand) capacity constraints.

\subsubsection{First-price equilibrium and revenue equivalence}

While Gale and Hausch (1994) consider the second-price sealed bid format we analyze endogenous entry in sequential procurement contracts by presenting the complete first-price equilibrium solution of the game. Although the second-price auction format is analytically more tractable it is rare in procurement such that deriving the non-trivial (see Katzman 1999, p. 78) first-price equilibrium is more predictive for real bidding behavior. Note that under the second-price format if there is competition in stage two, each bidder's dominant strategy is to bid its true completion cost while under the first-price design equilibrium strategies (including the entry strategy) for both auctions must be determined simultaneously (see also Gale and Hausch 1994, p. 321).

Revenue equivalence in one-shot auctions is well known. From Weber (1983) and Maskin and Riley (1989) we also know that in multi-unit auctions with identical objects and unit demand bidders revenue equivalence applies. For an auction setting with multiple non-identical (stochastically equivalent) objects and an endogenous number of bidders no such result has been shown yet. We prove revenue equivalence and show that equilibrium entry behavior is invariant to the particular auction design. Our result of revenue equivalence implies that all results on price-trends derived by Gale and Hausch (1994) in their second-price auction model apply to our model too.

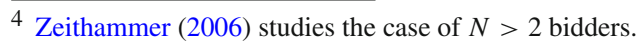




\subsubsection{Isobid curves in two-dimensional type space}

A key feature of our sequential procurement auction model is that bidders' types are two-dimensional (the cost value for the first auction along with the cost value for the second auction). Any analysis of bidding behavior with one-dimensional bids aggregates two-dimensional types into a single bid (e.g., the bid in the first procurement auction) which depends on some appropriately defined one-dimensional type. It follows that the same particular single bid value can be submitted by a continuum of newly defined one-dimensional types each generated by appropriate variations of two-dimensional types in both dimensions. From a geometric point of view, there arise isobid curves in two-dimensional type space. This approach was introduced in Che and Gale (1998). Che and Gale (1998) incorporate financial constraints into the SIPV model where the first dimension of the type is the value of the auctioned object and the second dimension is the financial constraint, e.g., the budget available for purchasing the object. Interestingly, equilibrium aggregation of two-dimensional types in Che and Gale (1998) leads to a (refined) minimum selection of type dimensions, the result that revenue equivalence does not hold and "Leontief" isobid curves for the first-price and second-price auction. In our paper, the second dimension is the cost of executing a project that is offered in a second auction which is related to the option value of winning the second auction. Here, type aggregation is facilitated by an affine function of both type dimensions, revenue equivalence prevails, and isobid curves take the form of straight lines.

\subsubsection{Asymmetric procurement auctions}

De Silva et al. (2003) provide an asymmetric, static bidding model to explore differences in bidding patterns observed in road construction auctions. In their model, firms' distributions of completion costs differ from one another which is motivated by the idea that firms are either incumbents or entrants implying that bidders with identical completion costs differ in bidding behavior; particularly, entrants bid more aggressively than incumbents which is statistically confirmed in their empirical analysis. In our paper, we provide an alternative explanation for differing bid functions in a symmetric, sequential auction model stemming from differences in the option value that firms assign to subsequently auctioned procurement contracts. In this spirit, our model may be viewed as a way to endogenize asymmetries and differences in bid functions in static models through heterogenous opportunity costs.

\section{Model and equilibrium}

Following the literature (e.g., Arozamena and Estelle 2006, or Porter and Zona 1993), we view first-price procurement auctions as low-bid auctions instead of high-bid auctions and interpret the winning bid as the price at which the service of project completion is sold to the procuring buyer. Our results would not have been substantially affected if we had analyzed a sequence of standard high-bid auctions with bidders facing unit demand. 
There are two risk-neutral firms, each endowed with capacity to complete a single project. ${ }^{5}$ Two projects, $L$ and $M$, are sequentially auctioned off. Subcontracting is prohibitively costly. ${ }^{6}$ The firms' cost of completing any of the two projects are their private information and known to them at the beginning of the dynamic auction game. In order to formalize the similarity of both projects and the aspect that the ranking of completion costs is unknown ${ }^{7}$ to competitors, we assume that projects are stochastically equivalent. In particular, it is common knowledge that firm $i$ 's costs of completion are jointly drawn from $f\left(l_{i}, m_{i}\right)$ with domain $[\underline{c}, \bar{c}]^{2}$ and stochastically equivalent in the sense of $f(l, m)=f(m, l)$ for every $(l, m) \in[\underline{c}, \bar{c}]^{2}$ implying $E\left[L_{i}\right]=E\left[M_{i}\right]$ where $l_{i}$ and $m_{i}$ denote the cost realization of firm $i$ for projects $L$ and $M$ respectively. Although completion costs of a single firm may be correlated across projects, pairs of completion costs of different firms are independently distributed. ${ }^{8}$ If cost realizations of firm $i$ are such that $l_{i}<m_{i}$, this firm is said to have a cost advantage for project $L$, the reversed inequality indicates a cost advantage for project $M$.

In each procurement auction, a participating firm may submit a sealed bid where the lowest bid wins the project and the amount bid is paid in exchange for completion of the project. ${ }^{9}$ However, bids cannot exceed maximum completion costs $\bar{c}$ which may be interpreted as the procurers outside option. We assume that the auctioneer cannot set a price below maximum completion costs $\bar{c}$ and that resale of projects is not feasible. If there happens to be a bidding tie, auctioneers employ a fair chance mechanism to break it. The sequence of auctions begins with the procurement auction of project $L$ where the winner, if there is any, is publicly announced before project $M$ is auctioned off. Thus, with two firms, any firm knows if it faces competition in auction $M$ before it submits its bid.

\footnotetext{
5 Although the restriction that firms are required to complete at most a single project seems severe, closer observation reveals that this element is common in procurement auctions. Firstly, procurers may stipulate exclusive project completion to avoid that its competitors running a similar project gain benefits through a contractor working for both procurers. Secondly, a firm may face capacity constraints if projects run simultaneously and require relatively large amounts of its resources. Finally, firms may voluntarily decide not to execute simultaneously several risky projects to prevent changes in the risk distribution of their entrepreneurial activities.

6 Empirical studies on procurement bidding (e.g., Jofre-Bonet and Pesendorfer 2000, 2003) find that the probability that a firm participates in an auction and that a participating firm wins the auction decreases in its backlog. This points to the fact that firms regard subcontracting as costly and not always as a feasible option to weaken their capacity constraints.

7 Unlike the second-price procurement auction model in Elmaghraby (2003) where it is assumed that the second project is always more costly than the first one.

${ }^{8}$ For any individual firm $i(i=1,2)$, we allow for any type of correlations between its random project costs $L_{i}$ and $M_{i}$ by letting them be jointly distributed according to the bivariate probability density function $f\left(l_{i}, m_{i}\right)$ such that stochastic equivalence is satisfied. This generality is possible since the analysis of the model does not rely on independent project cost distributions (which would imply $f\left(l_{i}, m_{i}\right)=$ $\left.f_{L}\left(l_{i}\right) \cdot f_{M}\left(m_{i}\right)\right)$, but utilizes the joint probability distribution function as a whole throughout the paper. Before the auction sequence, it is common knowledge that nature independently draws project completion cost pairs following $f\left(l_{i}, m_{i}\right)$ for each firm and privately reveals them. Realizations of project costs cannot be altered during the auction sequence, excluding the possibility to condition project completion costs on events during the auction sequence.

9 Although the analysis of the second-price auction design is less demanding, we employ the first-price design since otherwise our model's bidding predictions cannot explain real-life data.
} 
The dynamic auction game is a sequential game with incomplete information, hence, we confine our attention to perfect Bayesian equilibria. Importantly, a perfect Bayesian equilibrium provides a link between equilibrium beliefs and equilibrium strategies such that equilibrium strategies are optimal given equilibrium beliefs and equilibrium beliefs are consistent with equilibrium strategies and actual play. This circular reasoning requires the simultaneous determination of beliefs and strategies implying that our sequential auction game cannot be solved by backward induction. Instead we solve the entire game at once: We determine the Bayesian equilibrium of the "continuation game", i.e., the second auction game, given any set of a posteriori beliefs and solve for the Bayesian equilibrium in the first auction game given properties of the equilibrium in the continuation game. The final step for simultaneous equilibrium solution is to establish the link between a posteriori beliefs that are subject to Bayesian updating given entry behavior into the first auction and equilibrium entry behavior into the first auction.

Since both firms are ex ante symmetric, we restrict attention to the case of symmetric equilibria. We refer to the representative firm as firm 1 . The strategy of the representative firm is given by $\left(b_{1}^{L}, b_{1}^{M}\right)$ where the bid for auction $L$ is given by $b_{1}^{L} \in \mathbb{R} \cup\{$ no entry $\}$ and $b_{1}^{M} \in \mathbb{R}$ is the firm's bid in auction $M$. In addition to equilibrium bid functions for each auction stage, a firm's strategy also includes a decision to submit a bid in the first auction or skip bidding for project $L$. Intuitively, there must be a region of cost types where firms reject to bid in auction $L$ since a firm with completion cost $l=\bar{c}$ cannot make any profit by completing this project and, moreover, is-if it has won project $L$-excluded from participating in auction $M$ where its expected profits may be positive due to more favorable costs of completion $m<\bar{c}$. Obviously, these extreme cost pairs highlight that opportunity costs, which coincide with expected profits from skipping auction $L$, exceed expected profits from bidding for project $L$. In general, firm 1 participates in auction $L$ if its expected profit from bidding exceeds opportunity costs arising from possibly being excluded from bidding for project $M$, formally

$$
E\left[\Pi_{1}^{L+M} \mid\left(l_{1}, m_{1}\right)\right] \geq E\left[\Pi_{1}^{M} \mid m_{1}\right]
$$

where $E\left[\Pi_{1}^{L+M} \mid\left(l_{1}, m_{1}\right)\right]$ denotes firm 1's expected profit if it bids in the procurement auction for project $L$ and-if unsuccessful—continues bidding in auction $M$ and $E\left[\Pi_{1}^{M} \mid m_{1}\right]$ is its expected profit if it skips the first auction and bids only for the subsequently auctioned project $M$. Profits are random since completion costs of any competitor are unknown and determine its bidding behavior.

The firm's decision to skip auction $L$ depends on the relation of its completion costs. In order to formalize the entry decision we introduce the entry indifference curve $g_{1}:[\underline{c}, \bar{c}] \rightarrow[\underline{c}, \bar{c}]$ that assigns a value for the completion cost of project $L$ to each cost value of project $M$ such that the firm is indifferent between taking part in auction $L$ and skipping it. The entry indifference curve $l_{1}^{\text {crit }}=g_{1}\left(m_{1}\right)$ is implicitly defined by the equality of expected profits from entering auction $L$ and corresponding opportunity cost: 


$$
E\left[\Pi_{1}^{L+M} \mid\left(l_{1}^{\text {crit }}, m_{1}\right)\right]=E\left[\Pi_{1}^{M} \mid m_{1}\right]
$$

Since it cannot be worthwhile for a firm to participate in auction $L$ with $l_{1}>l_{1}^{\text {crit }}$ but it must be if $l_{1}<l_{1}^{\text {crit }}$, the firm's decision rule to participate in auction $L$ is given by

$$
\varepsilon_{1}\left(l_{1}, m_{1}\right)= \begin{cases}\text { Enter auction } L & \text { if } l_{1} \leq g_{1}\left(m_{1}\right) \\ \text { Skip auction } L & \text { if } l_{1}>g_{1}\left(m_{1}\right)\end{cases}
$$

In Sect. 2.2 we show that the entry indifference curve defined here exists. Figure 3 illustrates the qualitative properties of the entry indifference curve in equilibrium.

Next we derive the equilibrium bid functions for both procurement auctions since these determine expected profits on which the entry indifference curve $g_{1}\left(m_{1}\right)$ depends. Since the equilibrium bid functions depend on the equilibrium entry indifference curve themselves, we derive these for any entry indifference curve $g_{1}\left(m_{1}\right)$. The equilibrium indifference curve is denoted by $g(m)$ and is identified given equilibrium bidding behavior. Thus equilibrium bidding and the entry indifference curve are simultaneously determined.

\subsection{Equilibrium bid functions}

Both auctions employ the first-price sealed-bid auction format where the lowest bid wins. ${ }^{10}$ With first-price auctions, the symmetric equilibrium strategy in a one-shot procurement auction is well-known, e.g., Holt (1980) and Cohen and Loeb (1990), and summarized in Lemma 1.

Lemma 1 (Cohen and Loeb 1990) Equilibrium bidding in a first-price procurement auction. Let project completion costs of two risk-neutral firms that bid for a single project contract be private information and independently and identically distributed according to $c d f H(c), c \in[\underline{c}, \bar{c}]$.

Then, the symmetric equilibrium bid function is $b(c)=c+\int_{c}^{\bar{c}}[1-H(x)] \mathrm{d} x /$ $[1-H(c)]$.

For our sequential procurement auction game, we derive the equilibrium bid function for each of the two project auctions by application of this lemma to our specific context with additional strategic interaction: In the first auction stage every firm knows that a second auction follows. In the second auction stage, each bidder receives information on the outcome of the first auction $L$.

Figure 1 illustrates the equilibrium structure of the game. Consider first the auction for project $L$. Any of the two firms that enters the first auction anticipates that in case it does not win the first auction, it will be the only bidder in the subsequent auction $M$ where it will receive $\bar{c}-m$. Thus, it might submit a relatively high bid for project $L$, since it is, at least partially, insured against losing the first auction. In particular, a firm

$\overline{10}$ Cf. Vickrey (1961), McAfee and McMillan (1987a) or Milgrom (1989). 


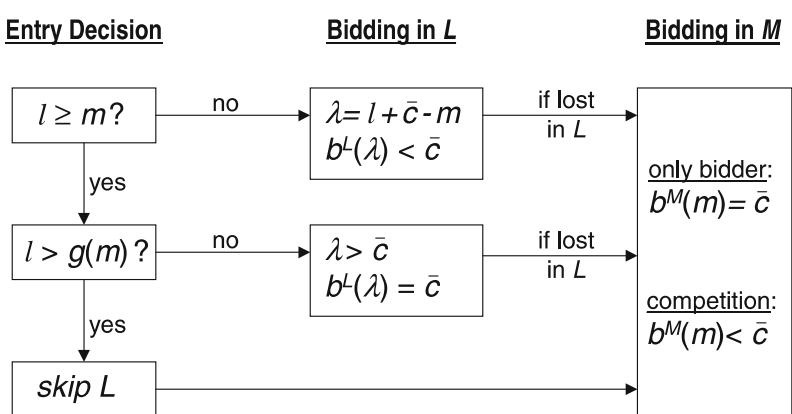

Fig. 1 Equilibrium structure of the sequential procurement auction game

with a cost advantage ${ }^{11}$ for project $M$ knows that the largest payoff it can receive is $\bar{c}-m$ from being the only bidder for project $M$ since its largest payoff in auction $L$ is $\bar{c}-l$ which must be smaller due to the firm's cost advantage. Thus, provided the firm decides to participate in auction $L$, it seeks to lose the first auction and minimizes its chances of winning project $L$ by submitting the highest feasible bid which simultaneously maximizes its payoff from accidentally winning it. In contrast, if a firm has a cost advantage for project $L$, then it tops its completion cost $l$ with its certain return from auction $M$ and uses this revised cost parameter $\lambda \equiv l+\bar{c}-m$ in auction $L$. Intuitively it uses its total cost of executing project $L$ that include the direct project cost $l$ and the opportunity cost of winning project $L, \bar{c}-m$ (=benefit of not-winning auction $L$ ): Any firm taking part in auction $L$ treats $\bar{c}-m$ as a safe profit; if it wins project $L$, it pays the cost of executing this project and "repays" the amount $\bar{c}-m$.

If there is no bidding competition in the auction for project $M$, then any firm bidding for it submits the maximum feasible bid to maximize profits. If it is not the only bidder then it receives the additional information that its competitor did not enter auction $L$, too. In response it updates its belief about its competitor's cost parameter for project $M$ since skipping auction $L$ might not be equilibrium behavior for every type. The appropriate a posteriori pdf is denoted by $f_{M \mid \text { skip }}(m)$ and gives the (equilibrium) density that a firm with completion cost realization $m$ for project $M$ bids only in auction $M$. Put differently, $f_{M \mid \text { skip }}(m)$ is the marginal pdf of $f(l, m)$ conditional on the fact that completion cost pair $(l, m)$ leads the firm to skip auction $L$.

The closed-form equilibrium bid functions for auctions $L$ and $M$ are stated in parts (a) and (b) of Proposition 2. In equilibrium, competitive bids equal project costs, including opportunity costs, augmented, i.e., "shaded", by an amount that depends on a firm's beliefs about the total project cost of its competitor, $F$.(.), and its own total project cost, $\lambda$. It is easy to see that equilibrium bids strictly increase in total cost value $\lambda$.

To explicitly obtain the first-price equilibrium bid function for the first auction using standard methods, it is essential that there is an additive relationship between project cost $l$ and opportunity cost $\bar{c}-m$ that manifests here in total cost parameter $\lambda \equiv l+\bar{c}-m$. The probability density function of $\lambda$ is derived from the joint

\footnotetext{
11 Recall that the term cost advantage refers to a comparison across projects rather than a comparison across firms.
} 
Fig. 2 Obtaining probability density function $f_{\lambda}(\lambda)$

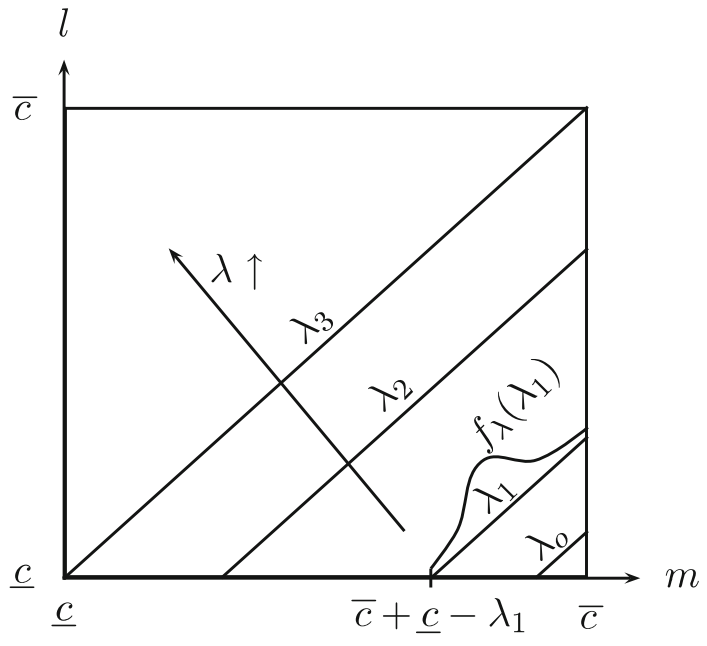

distribution $f(l, m)$ by integrating over all cost pairs $(l, m)$ that lead to the same total cost value $\lambda$. Figure 2 illustrates various isoquants of $\lambda$ in the type space. ${ }^{12}$ Integrating joint density $f(l, m)$ along isoquants yields the corresponding probability density for total cost value $\lambda$, in general $f_{\lambda}(\lambda)=\int_{\bar{c}+c-\lambda}^{\bar{c}} f(\lambda-\bar{c}+m, m) \mathrm{d} m$ for $\lambda \in[\underline{c}, \bar{c}]$.

The equilibrium bid function for the second auction depends on the outcome of the first auction. Whenever there is competition for project $M$, the firm submits a competitive bid that is smaller than reserve price $\bar{c}$. For the competitive equilibrium bid, the amount of shading depends on the marginal distribution of project costs for project $M$ that is conditioned on the fact the competitor did not enter the first auction. We compare equilibrium bid functions to SIPV counterparts in Sect. 4.

Proposition 1 Equilibrium bid functions in auctions $L$ and $M$. The equilibrium bid functions of a firm with completion cost pair $(l, m) \in[\underline{c}, \bar{c}]^{2}$ are given by:

(a) $b^{L}(\lambda)= \begin{cases}\bar{c} & \text { if } l \geq m \\ \lambda+\int_{\lambda}^{\bar{c}}\left[1-F_{\lambda}(x)\right] \mathrm{d} x /\left[1-F_{\lambda}(\lambda)\right] & \text { otherwise }\end{cases}$

if it submits a bid for project $L$ where $\lambda \equiv l+\bar{c}-m$ and $F_{\lambda}(x)=\int_{\underline{c}}^{x} \int_{\bar{c}+\underline{c}-\lambda}^{\bar{c}}$ $f(m-\bar{c}+\lambda, m) \mathrm{d} m \mathrm{~d} \lambda$ with $x \in[\underline{c}, \bar{c}]$.

(b) $\quad b^{M}(m)= \begin{cases}\bar{c} & \text { if } i t \text { is the only bidder } \\ m+\int_{m}^{\bar{c}}\left[1-F_{M \mid \operatorname{skip}}(x)\right] \mathrm{d} x /\left[1-F_{M \mid \text { skip }}(m)\right] & \text { otherwise }\end{cases}$

12 Since the equilibrium bid along any isoquant is constant in general, they are also called isobid lines, e.g., Che and Gale (1998). In our case, however, this 1:1 relationship between the type $\lambda$ and the equilibrium bid breaks down whenever there is a cost advantage for the second project, i.e., $\lambda \geq \bar{c}$, since in this case any type $\lambda \geq \bar{c}$ submits a bid of $\bar{c}$. In the context of Fig. 2 this means that any isoquant below $\lambda_{3}$ (where the one for $\lambda_{3}$ coincides with the $45^{\circ}$-line) corresponds to a unique isobid curve; in contrast the isobid curve for the largest feasible bid $\bar{c}$ does not correspond to a unique isoquant, rather it is an area defined as the set of types that faces a cost advantage for the second project and enters the first auction, i.e., $\lambda \geq \lambda_{3}$ and $\lambda \leq g(m)$. 
if it submits a bid for project $M$ where $f_{M \mid \text { skip }}(x)=\left[\int_{g(x)}^{\bar{c}} f(l, x) \mathrm{d} l\right]$ $/\left[\int_{\underline{c}}^{\bar{c}} \int_{g(t)}^{\bar{c}} f(l, t) \mathrm{d} l \mathrm{~d} t\right]$ and $F_{M \mid \text { skip }}(x)=\int_{\underline{c}}^{x} f_{M \mid \text { skip }}(s) \mathrm{d} s$ and $g(x)$ denotes the competitor's entry indifference curve.

Proof Consider first part (b): Before bidding for auction $M$, any firm knows if its competitor won auction $L$. If the competitor entered auction $L$, the firm remains the only bidder in auction $M$ and maximizes its return by submitting the largest feasible bid equaling $\bar{c}$. If, however, its competitor skipped auction $L$, the firm infers that its competitor's completion cost pair must satisfy $L>g(M)$ (to be determined later) and Bayesian updating of the firm's cost belief regarding its competitor leads to the a posteriori pdf $f_{M \mid \text { skip }}(x)$. Appealing to Lemma 1 leads to $b^{M}(m)$.

For (a), note that a firm receives $\bar{c}-m$ in auction $M$ if it loses auction $L$. If its completion costs satisfy $m \leq l$ then it cannot receive a larger return in auction $L, \bar{c}-m \geq \bar{c}-l$ by assumption. Thus the firm chooses to receive the largest feasible return from auction $L$ by bidding $\bar{c}$ which also maximizes the frequency it ends up with the larger return from auction $M$, provided it submits a bid for project $L$.

In case the firm has a cost advantage for project $L$, i.e., $l<m$, its expected profit from participating in auction $L$ with any bid $b_{1}^{L} \in[\underline{c}, \bar{c}]$ and possibly in auction $M$ is given by

$$
\begin{aligned}
E\left[\Pi_{1}^{L+M} \mid l_{1}<m_{1}\right]= & \left(b_{1}^{L}-l_{1}\right) \cdot \operatorname{Pr}\left(b_{1}^{L} \text { wins auction } L\right) \\
& +\left(\bar{c}-m_{1}\right) \cdot\left[1-\operatorname{Pr}\left(b_{1}^{L} \text { wins auction } L\right)\right] .
\end{aligned}
$$

Using firm 1's total cost parameter $\lambda_{1} \equiv l_{1}+\bar{c}-m_{1}$, this can be rewritten as

$$
E\left[\Pi_{1}^{L+M} \mid l_{1}<m_{1}\right]=\left(b_{1}^{L}-\lambda_{1}\right) \cdot \operatorname{Pr}\left(b_{1}^{L} \text { wins auction } L\right)+\bar{c}-m_{1} .
$$

From firm 1's perspective $\bar{c}-m_{1}$ is a known constant and its expected profit from bidding in auction $L, E\left[\Pi_{1}^{L+M} \mid l_{1}<m_{1}\right]$, is maximized if $b_{1}^{L}$ maximizes

$$
Z\left(\lambda_{1}\right):=\left(b_{1}^{L}-\lambda_{1}\right) \cdot \operatorname{Pr}\left(b_{1}^{L} \text { wins auction } L\right),
$$

where $l_{1}<m_{1} \Leftrightarrow \lambda_{1}<\bar{c}$ by definition. Suppose there exists a symmetric equilibrium bid function $b^{L}(\lambda)$ that maximizes $Z$ such that it is strictly increasing for $\lambda<\bar{c}$, $b^{L}(\lambda)<\bar{c}$ for $\lambda<\bar{c}$, and $b^{L}(\lambda)=\bar{c}$ for $\lambda \geq \bar{c}$. Since $b^{L}(\lambda)$ is strictly increasing on $[\underline{c}, \bar{c}]$, there exists an inverse on that domain denoted by $b^{-1, L}\left(b^{L}\right)$. Given that firm 1 's competitor adheres to this equilibrium bid function, firm 1 (with a cost advantage for project $L$ ) wins always the first round if its competitor has a cost advantage for project $M, \lambda_{2} \geq \bar{c}$. It wins project $L$ too, if it bids an amount that corresponds to a lower total cost type $\lambda_{1}=b^{-1, L}\left(b^{L}\right)$ than the one of its competitor $\lambda_{2}$. Denoting the cdf of total cost types by $F_{\lambda}(\lambda),(2)$ can be rewritten as ${ }^{13}$

\footnotetext{
13 Here the fact is used that types with a cost advantage for project $L$ always enter the first auction. This is formally confirmed in Lemma 3.
} 


$$
Z\left(\lambda_{1}\right)=\left(b_{1}^{L}-\lambda_{1}\right) \cdot\left[1-F_{\lambda}\left(b^{-1, L}\left(b_{1}^{L}\right)\right)\right]
$$

where $f_{\lambda}(\lambda)=\int_{\bar{c}+\underline{c}-\lambda}^{\bar{c}} f(m-\bar{c}+\lambda, m) \mathrm{d} m$ and $F_{\lambda}(\bar{c})=1 / 2$. If $b_{1}^{* L}$ maximizes $Z$ then $\partial Z^{*} / \partial b_{1}^{L}=0$ and differentiation of (3) at the optimum w.r.t. $\lambda_{1}$ yields

$$
\frac{\mathrm{d} Z^{*}}{\mathrm{~d} \lambda_{1}}=-\left[1-F_{\lambda}\left(b^{-1, L}\left(b_{1}^{* L}\right)\right] .\right.
$$

Integration in the boundaries $\left[\lambda_{1}, \bar{c}\right]$ together with the fact that in a Nash equilibrium $b_{1}^{* L}$ must coincide with the value of the equilibrium bid function at the true cost type $\lambda_{1}$ leads to

$$
Z^{*}(\bar{c})-Z^{*}\left(\lambda_{1}\right)=-\int_{\lambda_{1}}^{\bar{c}}\left[1-F_{\lambda}(x)\right] \mathrm{d} x .
$$

Since $b^{L}(\bar{c})=\bar{c}$, we have $Z^{*}(\bar{c})=0$ and obtain with (3) at its optimum the equilibrium bid function for $\lambda_{1}<\bar{c}$ :

$$
b^{L}\left(\lambda_{1}\right)=\lambda_{1}+\frac{\int_{\lambda_{1}}^{\bar{c}}\left[1-F_{\lambda}(x)\right] \mathrm{d} x}{1-F_{\lambda}\left(\lambda_{1}\right)} .
$$

\subsection{Entry decision}

In this section, we derive the entry indifference curve (1) given equilibrium bidding summarized in Proposition 1. Obviously the expected profit from bidding in auction $L$ and possibly in auction $M, E\left[\Pi_{1}^{L+M} \mid\left(l_{1}, m_{1}\right)\right]$, always exceeds the expected profit from skipping auction $L, E\left[\Pi_{1}^{M} \mid m_{1}\right]$ if firm 1 has a cost advantage for project $L$ (i.e., $\left.l_{1} \leq m_{1}\right)$ : the expected profit from entering auction $L$ and possibly $M$ is at least as large as $\bar{c}-m_{1}$. To see this suppose that the firm would bid $\bar{c}$ in auction $L$. Then it receives in expectation $\left(\bar{c}-l_{1}\right) \cdot \operatorname{Pr}($ won $L)+\left(\bar{c}-m_{1}\right) \cdot \operatorname{Pr}($ lost $L) \geq \bar{c}-m_{1}$. For any bid in auction $M$, the expected profit from skipping $L, E\left[\Pi_{1}^{M} \mid m_{1}\right]$, must be lower than $\bar{c}-m_{1}$ since there is a positive probability of bidding competition in auction $M$. It follows that (1) can only hold if $l_{1}^{\text {crit }}>m_{1}$ and that without loss of generality the entry indifference curve is defined by:

$$
E\left[\Pi_{1}^{L+M} \mid\left(l_{1}^{\text {crit }}>m_{1}, m_{1}\right)\right]=E\left[\Pi_{1}^{M} \mid m_{1}\right]
$$

In order to explicitly state equation (4), consider first its left-hand side. A firm with a cost advantage for project $M$ that enters auction $L$ bids $\bar{c}$ in auction $L$ and if it loses $\bar{c}$ in auction $M$. This strategy results in four events summarized in the next table where 
the probabilities depend on firm 1's belief that firm 2 acts in accordance with the entry indifference curve $g_{2}\left(M_{2}\right)$.

\begin{tabular}{|ll|c|c|}
\hline & Events if firm 1 bids $\bar{c}$ in auction $L$ & Payoff & Probability \\
\hline A & it is the only bidder & $\bar{c}-l_{1}$ & $\operatorname{Pr}\left(L_{2}>g_{2}\left(M_{2}\right)\right)$ \\
B & the competitor bids $\bar{c}$ and firm 1 wins $L$ & $\bar{c}-l_{1}$ & $\operatorname{Pr}\left(g_{2}\left(M_{2}\right) \geq L_{2} \geq M_{2}\right) \cdot 0.5$ \\
C & the competitor bids $\bar{c}$ and firm 1 loses $L$ & $\bar{c}-m_{1}$ & $\operatorname{Pr}\left(g_{2}\left(M_{2}\right) \geq L_{2} \geq M_{2}\right) \cdot 0.5$ \\
D & the competitor bids less than $\bar{c}$ & $\bar{c}-m_{1}$ & $\operatorname{Pr}\left(L_{2}<M_{2}\right)$ \\
\hline
\end{tabular}

Hence the expected benefit to a firm with a cost advantage for project $M$ from starting bidding for project $L$ with $b^{L}=\bar{c}$ and then continuing bidding in auction $M$ after losing auction $L$ is given by

$$
\begin{aligned}
E & {\left[\Pi_{1}^{L+M} \mid\left(l_{1}>m_{1}, m_{1}\right)\right] } \\
& =\int_{\underline{c}}^{\bar{c}} \int_{g_{2}\left(m_{2}\right)}^{\bar{c}} f\left(l_{2}, m_{2}\right) \mathrm{d} l_{2} \mathrm{~d} m_{2} \cdot\left(\bar{c}-l_{1}\right) \\
& +\int_{\underline{c}}^{\bar{c}} \int_{m_{2}}^{g_{2}\left(m_{2}\right)} \frac{f\left(l_{2}, m_{2}\right)}{2} \mathrm{~d} l_{2} \mathrm{~d} m_{2} \cdot\left[2 \bar{c}-\left(l_{1}+m_{1}\right)\right] \\
& +\int_{\underline{c}}^{m_{2}} \int_{\underline{c}}^{m_{2}} f\left(l_{2}, m_{2}\right) \mathrm{d} l_{2} \mathrm{~d} m_{2} \cdot\left(\bar{c}-m_{1}\right) .
\end{aligned}
$$

Now, consider the right-hand side of (4). If firm 1 skips auction $L$ there are three events depending on the entry behavior of its competitor. Again firm 1 assesses the probabilities of these events given its belief about the competitor's entry indifference curve $g\left(M_{2}\right)$.

\begin{tabular}{|ll|c|c|}
\hline & Events if firm 1 skips auction $L$ & Payoff & Probability \\
\hline E & no bidding competition & $\bar{c}-m_{1}$ & $\operatorname{Pr}\left(L_{2} \leq g_{2}\left(M_{2}\right)\right)$ \\
F & firm 1 wins project $M$ & $b^{M}\left(m_{1}\right)-m_{1}$ & $\operatorname{Pr}\left(M_{2}>m_{1} \wedge L_{2}>g_{2}\left(M_{2}\right)\right)$ \\
G & the competitor wins project $M$ & 0 & $\operatorname{Pr}\left(M_{2}<m_{1} \wedge L_{2}>g_{2}\left(M_{2}\right)\right)$ \\
\hline
\end{tabular}

Thus the expected benefit to firm 1 with a cost advantage for project $M$ from skipping bidding for project $L$ can be written as:

$$
\begin{aligned}
E\left[\Pi_{1}^{M} \mid m_{1}\right]= & \left(\bar{c}-m_{1}\right) \int_{\underline{c}}^{\bar{c}} \int_{\underline{c}}^{g_{2}\left(m_{2}\right)} f\left(l_{2}, m_{2}\right) \mathrm{d} l_{2} \mathrm{~d} m_{2} \\
& +\int_{m_{1}}^{\bar{c}} \int_{g_{2}\left(m_{2}\right)}^{\bar{c}}\left[b^{M}\left(m_{1}\right)-m_{1}\right] \cdot f\left(l_{2}, m_{2}\right) \mathrm{d} l_{2} \mathrm{~d} m_{2} .
\end{aligned}
$$

A standard result in auction theory is that in first-price sealed-bid auctions bids are formed such that they equal the expected second-order statistic from the relevant type 
pool (conditional on the own type being the first-order statistic). Thus, $b^{M}\left(m_{1}\right)$ in the last term in $E\left[\Pi_{1}^{M} \mid m_{1}\right]$ can be substituted by $m_{2}$. This is formally confirmed by Lemma 2 implying:

$$
\begin{aligned}
E\left[\Pi_{1}^{M} \mid m_{1}\right]= & \left(\bar{c}-m_{1}\right) \int_{\underline{c}}^{\bar{c}} \int_{\underline{c}}^{g_{2}\left(m_{2}\right)} f\left(l_{2}, m_{2}\right) \mathrm{d} l_{2} \mathrm{~d} m_{2} \\
& +\int_{m_{1}}^{\bar{c}} \int_{g_{2}\left(m_{2}\right)}^{\bar{c}}\left(m_{2}-m_{1}\right) \cdot f\left(l_{2}, m_{2}\right) \mathrm{d} l_{2} \mathrm{~d} m_{2} .
\end{aligned}
$$

Clearly $E\left[\Pi_{1}^{M} \mid m_{1}\right]$ decreases in $m_{1}$ and is independent of $l_{1}$.

Lemma 2 Firm 1's expected profit from equilibrium bidding in auction $M$ if there is bidding competition and $b_{1}^{M}=b^{M}\left(m_{1}\right)$ is equal to the expected profit from bidding the expected second-order statistic of completion costs given that firm 1's completion costs are the lowest, i.e.,

$$
\int_{m_{1}}^{\bar{c}} \int_{g_{2}\left(m_{2}\right)}^{\bar{c}}\left(b_{1}^{M}-m_{1}\right) \cdot f\left(l_{2}, m_{2}\right) \mathrm{d} l_{2} \mathrm{~d} m_{2}=\int_{m_{1}}^{\bar{c}} \int_{g_{2}\left(m_{2}\right)}^{\bar{c}}\left(m_{2}-m_{1}\right) \cdot f\left(l_{2}, m_{2}\right) \mathrm{d} l_{2} \mathrm{~d} m_{2} .
$$

Proof See the Appendix.

Lemma 3 Boundaries of the entry indifference curve $g(m)$

Let $l_{1}^{\text {crit }}=g_{1}\left(m_{1}\right)$ be implicitly defined by $E\left[\Pi_{1}^{L+M} \mid\left(l_{1}^{\text {crit }}, m_{1}\right)\right]=E\left[\Pi_{1}^{M} \mid m_{1}\right]$. If $g_{1}\left(m_{1}\right)$ exists, then $m_{1}<g_{1}\left(m_{1}\right)<\bar{c}$ for $m_{1} \in[\underline{c}, \bar{c})$ and $g_{1}(\bar{c})=\bar{c}$.

Proof See the Appendix.

The existence of the entry indifference curve in symmetric equilibrium is verified in Proposition 2 where also its properties are given. Its proof contains a differential equation whose solution is the symmetric equilibrium indifference curve $g(m)$. Figure 3 illustrates these results for a representative firm with completion cost pair $(l, m)$.

Proposition 2 For the symmetric perfect Bayesian equilibrium characterized by the representative firm's strategy $\left[b^{L}(l, m), b^{M}(m), \varepsilon(m)\right]$ and the density function $f(l, m)$ :

(a) There exists a (non-empty) compact and convex set of completion cost pairs where a firm bids for project $L$ although it has a cost advantage for completing project $M$. This subset is defined by $G=\left\{(l, m) \in[\underline{c}, \bar{c}]^{2} \mid m \leq l \leq g(m)\right\}$.

(b) The critical value function $g(m)$ exists and

(i) $m<g(m)<\bar{c}$ if $m \in[\underline{c}, \bar{c}), g(\bar{c})=\bar{c}, g(\underline{c})>\underline{c}$,

(ii) $g^{\prime}(m)>0$,

(iii) $g^{\prime \prime}(m)<0$ if $m \in[\underline{c}, \bar{c})$ and $g^{\prime \prime}(\bar{c})=0$. 
Fig. 3 Equilibrium entry behavior

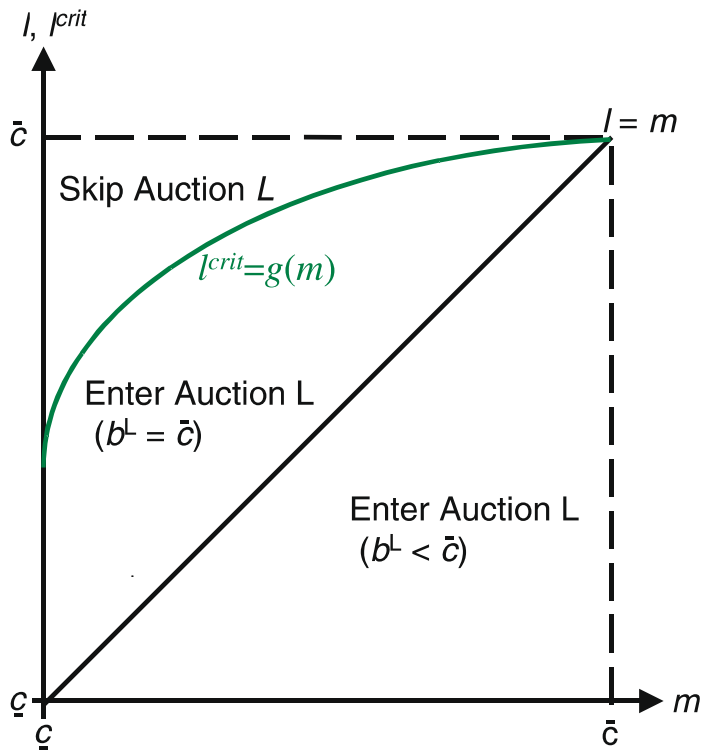

Proof See the Appendix.

Consideration of Proposition 2 leads to the conclusion that any firm always enters auction $L$ if it faces a cost advantage for this project, i.e., $l \leq m$. Then it earns at least $\bar{c}-m$ while skipping auction $L$ leaves it with running the risk of lower profits in case its competitor also skipped the first auction resulting in lower expected profits of this strategy. In contrast, a cost advantage for completing project $M$ implies the impossibility of the firm to secure itself the same return in auction $L$ as it could earn in auction $M$ being the only bidder. However, if the competing firm has a strong cost advantage for project $M$ and skipped auction $L$, then there is competition in the second auction with the risk of low or even zero profits due to aggressive bidding. Therefore a firm may wish to participate in the first auction and win the unloved project $L$ at a high price to insure itself against low profits resulting from fierce competition in the second auction, although it actually prefers losing the auction for project $L$.

Although our sequential auction model is highly stylized in the sense that we assume just two bidders implying that there is the possibility of being the sole bidder in the second auction, we conjecture that our results apply also for a more general number of bidders. ${ }^{14}$

As procurement contracts are usually auctioned off in the first-price format we derived equilibrium bid functions and entry decisions for this auction format. An immediate question that arises is, how these results and their implications depend on the specific auction design employed. In the next section, we show that revenue equivalence applies for this sequential auction model.

\footnotetext{
14 In particular we conjecture that in symmetric equilibrium with $N>2$ firms with first-price auctions, (a) the probability that a firm wins with a bid equal to the reserve price is strictly positive and (b) the probability that no firm enters the first auction is strictly positive.
} 
When firms with capacity to complete a single project know that a sequence of procurement contracts is offered, future contracting opportunities create an option value that influences today's bidding behavior. In Sect. 4 we analyze this option value adopting equilibrium bidding behavior derived in this section. Specifically, we demonstrate how the option value changes equilibrium bidding compared to the one-shot SIPV model.

\section{Payoff and revenue equivalence}

In this section we state a revenue equivalence result for our sequential auction model with non-identical bidder costs across projects. For a sequential auction of identical objects with bidders that demand a single object, revenue equivalence holds (Weber 1983; Maskin and Riley 1989). For our auction model it is a priori unclear if a similar revenue equivalence result continues to apply since in our model bidders' cost types for various projects are non-identical.

For a sequence of two completely unrelated standard auctions, i.e., two subsequent one-shot auctions, it is obvious that revenue equivalence holds in each of the "stage" auctions (Myerson 1981; Riley and Samuelson 1981). In our sequence of auctions, the number of bidders in the first stage auction is not fixed and the number of buyers in the second stage auction is unknown ex ante, ${ }^{15}$ so that our result extends standard revenue equivalence.

\subsection{Equivalence result}

Following Riley and Samuelson (1981), we impose the following five properties on auction designs adapted to our context that guarantee revenue equivalence for a class of auctions. Property A5 is motivated by our procurement context where we require the buyer to compensate any types' cost but not more and not less.

A1 The project buyer accepts a bid of every firm unless it exceeds the largest feasible bid.

A2 The project is awarded to a firm that submits the lowest bid.

A3 The auction design does only discriminate between bidders on the basis of submitted bids.

A4 There exists a symmetric Bayesian equilibrium with an increasing bid function.

A5 The auction design pays only amounts in the interval $[\underline{c}, \bar{c}]$ to a bidding firm. Furthermore, it guarantees that the highest cost-type receives a compensation equal to its cost $\bar{c}$.

Definition 1 Auction class $\Gamma$ comprises all auction designs satisfying properties $A 1-A 5$.

\footnotetext{
15 In the first stage auction the number of bidders is 0,1 or 2 ; in the second stage auction it is either 1 or 2.
} 


\section{Lemma 4 Expected profit if skipping auction $L$.}

(a) No competition in M: Suppose that there is a single bidder in the second auction $M$. Then, the bidder's expected profit is given by $\pi_{1}^{M \mid N C}\left(m_{1}\right)=\bar{c}-m_{1}$.

(b) Competition in M: Suppose that there are two bidders in the second auction $M$. Then, bidder 1's expected profit is given by $\pi_{1}^{M \mid C}\left(m_{1} \mid g_{2}().\right)=\int_{m_{1}}^{\bar{c}}[1-$ $\left.F_{M \mid \text { skip }}(s)\right] \mathrm{d} s$ where the distribution is defined as in Proposition 1.

(c) Ex ante profit from skipping auction L: Suppose that a bidder considers skipping the first auction $L$. Then, his expected profit is given by $E\left[\Pi^{M} \mid m_{1} ; g_{2}().\right]=$ $p^{\text {skip } \mid g_{2}(.)} \cdot \pi_{1}^{M \mid C}\left(m_{1}\right)+\left[1-p^{\text {skip } \mid g_{2}(.)}\right] \cdot \pi_{1}^{M \mid N C}\left(m_{1} \mid g_{2}().\right)$ where $p^{\text {skip } \mid g_{2}(.)}$ denotes the probability that the competitor skips the first auction implying competition in the second auction conditional on entry behavior of the competitor, i.e., $p^{\text {skip } \mid g_{2}(.)}=\int_{\underline{c}}^{\bar{c}} \int_{g_{2}(m)}^{\bar{c}} f(l, m) \mathrm{d} l \mathrm{~d} m$.

Proof (a) By A5, the largest buyer payment to a firm is $\bar{c}$ since the auction design guarantees that the project cost of the highest cost-type is fully covered. If there is no competition, the only bidder bids such that it pretends to have to incur maximum cost $\bar{c}$ which it precisely receives.

(b) In auction $M$ with competition, there are two bidders that have observed that the competitor did not enter auction $L$. Each bidder updates the distribution about

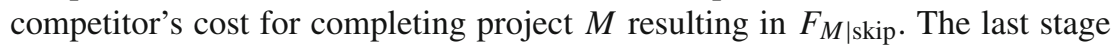
of the sequential auction game can be viewed as a standard ${ }^{16}$ one-shot auction with a modified distribution, the result immediately follows.

(c) The given expression is the definition of the expected firm's profit if skipping auction $L$.

Proposition 3 (Payoff equivalence) If the two auction designs utilized in auctions $L$ and $M$ are in class $\Gamma$, each firm's expected equilibrium profit is independent of the particular auction design and there is invariance of equilibrium entry behavior.

Proof We have to show that each cost type $\left(l_{1}, m_{1}\right)$ receives the same expected profit in equilibrium. Our strategy of proof is as follows: first, we show that a firm with a cost advantage for the first project, i.e., $l_{1}<m_{1}$, always enters the first auction and receives the same expected profit from its equilibrium strategy "enter $L$ and possibly $M$ (where $l_{1}<m_{1}$ )" independently of the auction designs utilized in $L$ and $M$. Second, we show that for a given entry indifference curve, changes in the auction design do not change expected profits from the strategies "enter $L$ and possibly $M$ (where $l_{1} \geq m_{1}$ )" and "skip $L "$.

\footnotetext{
16 The sense in which the second auction is not standard is that the number of bidders varies, it is either one or two, which is publicly known before bids are submitted in the second auction and that bidders hold posterior beliefs. If a firm realizes that it is the only remaining bidder, it is dominant to submit the largest feasible bid, $\bar{c}$, for each possible posterior belief about its competitor (which does not enter the auction). If, however, a firm finds that also its competitor bids in the second auction (which is known since the first project was not allocated to any firm), a similar situation as in the "standard one-shot auction set-up" unfolds with the exception that each firm received a signal (the competitor did not enter the first auction) about the type of the competitor. Given Bayesian updating of prior beliefs, the second auction with competition is standard in the sense that the "same" equilibrium bid function albeit with a different, updated probability density is used as equilibrium bid function for the second auction.
} 
1. If a firm with a cost advantage for the first project, i.e., $l_{1}<m_{1}$, does not enter the first auction, its expected profit cannot exceed $\bar{c}-m_{1}$ due to the fact that $\bar{c}$ is the largest payment that any auction design in class $\Gamma$ allows. However, since $\bar{c}-l_{1}>\bar{c}-m_{1}$, entering the first auction always offers the possibility to earn a higher expected profit.

Now we derive the expected equilibrium profit if a firm with a cost advantage for project $L$ enters the first auction. Let the specific payment rule according to auction design $L$ to bidder 1 be given by the function $\rho^{L}\left(b_{1}^{L}, b_{2}^{L}\right)$ where $b_{i}^{L}$ specifies the bid of bidder $i$ in auction $L$. Assuming that there exists an equilibrium bidding strategy $b^{L}: \mathbb{R} \rightarrow \mathbb{R} \cup\{$ no entry\} that is strictly increasing on $[c, \bar{c}]$ and that firm 2 follows where $\lambda_{2}=l_{2}+\bar{c}-m_{2}$, firm 1's expected payment from imitating type $x_{1}$ in auction $L$ is $R^{L}\left(x_{1}\right)=E\left[\rho^{L}\left(b^{L}\left(x_{1}\right), b^{L}\left(\lambda_{2}\right)\right)\right]$ and the firm's equilibrium profit is:

$$
E\left[\Pi^{L+M} \mid l_{1}<m_{1}\right]=R^{L}\left(x_{1}\right)-\operatorname{Pr}\{\operatorname{win} L\} l_{1}+[1-\operatorname{Pr}\{\operatorname{win} L\}]\left(\bar{c}-m_{1}\right),
$$

which can be rewritten as

$$
E\left[\Pi^{L+M} \mid l_{1}<m_{1}\right]=R^{L}\left(x_{1}\right)-\left[1-F_{\lambda}\left(x_{1}\right)\right] \lambda_{1}+\bar{c}-m_{1},
$$

where $\lambda_{1}=l_{1}+\bar{c}-m_{1}$ and $F_{\lambda}($.$) is defined as in Proposition 1. E\left[\Pi^{L+M} \mid l_{1}<m_{1}\right]$ is maximized if $Q=R^{L}\left(x_{1}\right)-\left[1-F_{\lambda}\left(x_{1}\right)\right] \lambda_{1}$ is maximized. $Q$ can be interpreted as the expected profit if opportunity costs are included. Maximizing $Q$ leads to the following FOC for all $\lambda_{1} \in[\underline{c}, \bar{c})$ at the Nash optimum $\lambda_{1}=x_{1}$

$$
\frac{\mathrm{d} R^{L}\left(x_{1}\right)}{\mathrm{d} x_{1}}=-\frac{\mathrm{d} F_{\lambda}\left(x_{1}\right)}{\mathrm{d} x_{1}} \lambda_{1} .
$$

After substituting the Nash condition $\lambda_{1}=x_{1}$ and integration in the boundaries $\left[\lambda_{1}, \bar{c}\right]$ we obtain

$$
R^{L}\left(\lambda_{1}\right)=R^{L}(\bar{c})+\int_{\lambda_{1}}^{\bar{c}} s \mathrm{~d} F_{\lambda}(s) .
$$

Note that $R^{L}\left(\lambda_{1}\right)$ is discontinuous at $\lambda_{1}=\bar{c}$ and the left-side $\operatorname{limit}$ is $\lim _{\lambda_{1} \rightarrow \bar{c}^{-}}=$ $\frac{\bar{c}}{2} \cdot{ }^{17}$ If $\lambda_{1}=\bar{c}$ the firm bids as if it faces maximum cost for project $L$ and receives payment $\bar{c}$ if it wins the auction. However, it wins the auction only if firm 2 has no cost advantage for project $L$ and skips the auction or if it is favored by a fair

$\overline{17 \text { Every type } \lambda \in[\underline{\mathrm{c}}, \bar{\lambda}] \text { with } \bar{\lambda}}=2 \bar{c}-\underline{c}$, or equivalently each type with no cost advantage for auction $L$, i.e., $l \geq m$, either skips auction $L$ or bids as if having maximum $\operatorname{cost} \bar{c}$ for project $L$. It follows from the increasing bidding function $b^{L}$ (.) that every firm with a cost advantage for auction $L(\lambda<\bar{c})$ wins the auction if the competitor has no cost advantage for project $L(\lambda \geq \bar{c})$. The probability that the competitor has no cost advantage for project $L$ is $1 / 2$. Since the highest auction payment in auction $L$ to a bidder with maximum cost is $\bar{c}$, the expected payment from bidding in auction $L$ converges to $\bar{c} / 2$ as a firm's type approaches $\bar{c}$. 
coin flip due to a bidding tie. It follows that the probability that the firm wins $\bar{c}$ is strictly less than $1 / 2$ implying the discontinuity of $R^{L}\left(\lambda_{1}\right)$. Since $R^{L}(\bar{c})$ in Eq. (6) is the upper limit of an integral, we can use its left-side limit to substitute it in (6) which yields after integration by parts of the second term

$$
R^{L}\left(\lambda_{1}\right)=\bar{c}-F_{\lambda}\left(\lambda_{1}\right) \lambda_{1}-\int_{\lambda_{1}}^{\bar{c}} F_{\lambda}(s) \mathrm{d} s \text { if } l_{1}<m_{1} \Leftrightarrow \lambda_{1}<\bar{c} .
$$

The expression $R^{L}\left(\lambda_{1}\right)$ gives the expected equilibrium payment in auction $L$ to firm 1 faced with a cost advantage for project $L$. Since a firm's cost type is invariant to changes of the auction design, it follows that the expected profit for firms with a cost advantage for project $L$ is independent of the particular auction design if it is in class $\Gamma$.

2. Using the fact that only firms with no cost advantage for project $L$ skip the first auction (see the first part of the given proof), the entry indifference curve is defined by

$$
E\left[\Pi^{L+M} \mid\left(l^{\text {crit }}>m, m\right)\right]=E\left[\Pi^{M} \mid m\right],
$$

where $l^{\text {crit }}=g(m)$. For the setting where both auctions are in the first-price design, we have already shown that there exists an entry indifference curve, here denoted by $g^{\mathrm{fp}}(m)$, such that $(7)$ holds. Here we show that, given entry indifference curve $g^{\mathrm{fp}}($.), any combination of auction designs in class $\Gamma$ utilized in auctions $L$ and $M$, leaves the expected payoffs $E\left[\Pi^{L+M} \mid(l>m, m) ; g^{\mathrm{fp}}().\right]$ and $E\left[\Pi^{M} \mid m ; g^{\mathrm{fp}}().\right]$ unaffected, so that (7) continues to hold and $g^{\mathrm{fp}}($.) is an equilibrium entry indifference curve for any combination of auctions designs in $\Gamma$. Lemma 4 demonstrates that $E\left[\Pi^{M} \mid m, g^{\mathrm{fp}}().\right]$ is invariant to arbitrary changes of the auction designs. To see that $E\left[\Pi^{L+M} \mid(l>m, m) ; g_{2}().\right]$ is invariant to arbitrary changes of the auction design, consider its definition:

$$
\begin{aligned}
E\left[\Pi_{1}^{L+M} \mid\left(l_{1}>m_{1}, m_{1}\right) ; g_{2}(.)\right]= & p^{\text {skip } \mid} g_{2}(.) \cdot\left(\bar{c}-l_{1}\right) \\
& +\left[\frac{1}{2}-p^{\text {skip } \mid g_{2}(.)}\right] \cdot \frac{\bar{c}-l_{1}+\bar{c}-m_{1}}{2} \\
& +\frac{1}{2} \cdot\left(\bar{c}-m_{1}\right) .
\end{aligned}
$$

The first line A corresponds to the event that the other firm skips the first auction. Since the firm has no cost advantage for the project $L$, it bids in auction $L$ as if it has maximum cost for project $L$ and therefore receives in the event of winning auction $L$ the payment $\bar{c}$. With probability of $\frac{1}{2}$, the competitor has no cost advantage for project $L$. It follows that the probability that the firm has no cost advantage and does not skip auction $L$ is $\frac{1}{2}-p^{\text {skip } \mid g_{2}(.)}$. In this event, line $\mathrm{B}$, there is a bidding tie in auction $L$ that is fairly resolved. The third line, $\mathrm{C}$, gives the expected profit if the competitor has a cost advantage for project $L$ and, hence, bids as if it is a better cost type than $\bar{c}$ and always wins the first auction. Then, firm 1 is the only bidder 
in the second auction and receives $\bar{c}-m_{1}$. Since these arguments are independent of utilized auction designs, the invariance of $E\left[\Pi_{1}^{L+M} \mid\left(l_{1}>m_{1}, m_{1}\right) ; g_{2}().\right]$ completes the proof.

Corollary 1 For any combination of auction designs utilized in class $\Gamma$ for auctions $L$ and $M$ there is revenue equivalence in the sense that each firm receives the same expected payment in each stage auction implying that expected prices and buyers' expected payoffs are constant in each stage auction.

\subsection{Illustration of equivalence result}

Here we illustrate the equivalence result more tangibly using the equilibrium solution of the sequential auction model for our first-price auction design alongside with the solution for the second-price auction design. The second-price auction equilibrium is due to Gale and Hausch (1994). In Proposition 4 we state the symmetric second-price equilibrium for our procurement context to facilitate easier comparison. Here it is the lowest bid that wins the second-price auction instead of the highest one as in Gale and Hausch (1994).

Proposition 4 (Gale and Hausch 1994) Symmetric equilibrium with second-price auctions.

The equilibrium bid functions of a firm with completion cost pair $(l, m) \in[\underline{c}, \bar{c}]^{2}$ facing second-price auctions are given by:

(a) $b^{L, S P}(\lambda)=\left\{\begin{array}{ll}\lambda & \text { if } l \leq m \Leftrightarrow \lambda \leq \bar{c} \\ \bar{c} & \text { if } l>m \Leftrightarrow \lambda>\bar{c}\end{array} \quad\right.$ if it submits a bid for project $L$.

(b) $b^{M, S P}(m)=m$ if it submits a bid for project $M$.

(c) Entry behavior into the first auction for project $L$ is characterized by the entry indifference curve $g(m)$ as stated in Proposition 2. In particular, a firm bids in the first auction if $l \leq g(m)$, otherwise it does not participate in the first auction.

Proof To derive (b) consider a Vickrey argument: $b^{M, \text { SP }}$ only deviates in payoff for the firm if overbidding with $\widehat{b}$ leads a competitor to win with bid $\bar{b}$ where $\widehat{b}>\bar{b}>m$ or underbidding with $\widehat{b}$ to win project $M$ where $\widehat{b}<\bar{b}<m$. In the first case, $b^{M, \text { SP }}=m$ leads to the additional payoff $\bar{b}-m$, in the second case, underbidding results in the loss $m-\bar{b}$ while $b^{M, \text { SP }}=m$ guarantees zero profits. Since in all other cases the strategies over- and underbidding and the bidding strategy $b^{M, S P}=m$ lead to identical payoffs, the latter is a weakly dominant strategy in auction stage $M$.

For (a), at first consider $l \leq m$ : If both firms submit bids for project $L$, the representative firm anticipates that it receives $\bar{c}-m$ in the second auction if it does not win project $L$. Thus, true completion costs including opportunity costs are given by $\lambda=\bar{c}-m+l$. A Vickrey argument analogous to the one given for (b) reveals optimality of $b^{L, \mathrm{SP}}=\lambda$. If the representative firm is the only bidder for project $L$, any bid guarantees it the surplus $\bar{c}-l$, therefore bidding $\lambda$ is a weakly dominant strategy if $l \leq m$. Now suppose $l>m$ : Clearly, the representative firm cannot secure itself return $\bar{c}-m$ in auction $L$ since this requires a bid exceeding $\bar{c}$. If, however, the firm 
Table 1 First-price auction (FPA) and second-price auction (SPA) equilibrium results

\begin{tabular}{|c|c|c|}
\hline & FPA & SPA \\
\hline Eq. bid for $\mathrm{L}$ & $\begin{cases}100 & \text { if } \lambda \geq 100 \\
\frac{2}{3} \frac{\lambda^{3}-30 \lambda^{2}-1,660,000}{\lambda^{2}-40 \lambda-12,400} & \text { otherwise }\end{cases}$ & $\begin{cases}100 & \text { if } \lambda \geq 100 \\
\lambda & \text { otherwise }\end{cases}$ \\
\hline Eq. bid for M & $\begin{cases}100 & \text { if only bidder } \\
m+\frac{0.5839(m-100)+14.11\left[e^{A(m)}-e^{-A(m)}\right]}{0.292\left[e^{A(m)}+e^{-A(m)}\right]-0.5839} \text { otherwise }\end{cases}$ & $m$ \\
\hline $\begin{array}{l}\text { Enter } L \\
\quad \text { if } l \leq g(m)\end{array}$ & $g(m)=100+8.938\left[e^{-A(m)}-e^{A(m)}\right]$ & as in FPA \\
\hline $\begin{array}{l}\text { E[payoff] if } \\
\text { entering } L\end{array}$ & $\begin{cases}100-0.634 m-0.366 l & \text { if } \lambda \geq 100 \\
\frac{4475}{24}-\frac{1}{19200} \lambda^{3}+\frac{1}{640} \lambda^{2}-\lambda-m & \text { otherwise }\end{cases}$ & as in FPA \\
\hline $\begin{array}{l}\mathrm{E}[\text { payoff }] \text { if } \\
\text { not entering } \mathrm{L}\end{array}$ & $0.6338(100-m)+3.262\left[e^{B(m)}-e^{-B(m)}\right]$ & as in FPA \\
\hline
\end{tabular}

Note: $A(m)=\frac{100-m}{48.332}$ and $B(m)=-\frac{103}{5000}(m-100)$

submits a bid for project $L$, it submits the largest feasible bid, i.e., $\bar{c}$. Depending on the bidding behavior of the other firm, it receives either $\bar{c}-l$ or $\bar{c}-m$ where the latter exceeds the former. If it submits any lower bid in auction $L$ than $\bar{c}$, it reduces its expected profit since it receives a lower return from bidding in auction $L$ and increases the probability of winning the low prize. Thus bidding $b^{L, S P}=\bar{c}$ for $l>m$ is optimal.

Part (c) of the proposition is an implication of our equivalence result and invariant entry behavior as given in Proposition 3 since the second-price auction belongs to auction class $\Gamma$.

For the purpose of illustration, assume that completion costs are uniformly distributed on $[\underline{c}, \bar{c}]^{2}=[20,100]^{2}$ implying that the opportunity cost augmented cost parameter $\lambda$ for the first project is given by $\lambda=l+100-m$. Table 1 compares symmetric equilibrium results ${ }^{18}$ of the first-price design to that of the second-price design. Although the equilibrium bids for the first and second project differ under both auction designs, entry behavior and expected payoffs are the same in equilibrium.

\section{The impact of endogenous outside options on bidding behavior}

In contrast to one-shot auctions, in the dynamic auction model there is an alternative transaction opportunity available to bidders. Firstly, we analyze how the option value created by the second auction affects bids in the first auction. Secondly, we show that the static SIPV equilibrium bid function is no special case in any auction of the dynamic model, even for bidders facing no opportunity cost. Thirdly, we compare equilibrium bidding in the dynamic model to that in the static model.

\footnotetext{
18 For the detailed derivation of the numerical results see Reiß and Schöndube (2007).
} 
4.1 Better outside options yield less aggressive bids ceteris paribus

The option value due to the opportunity to participate in the second auction depends on a firm's completion cost for the second project. If a firm bids in the first auction its opportunity cost of winning is $\bar{c}-m$ since not winning the first auction renders it the only bidder in the second auction. A greater option value $\bar{c}-m$ moves the bid function upwards and implies less aggressive bids. For verification we differentiate the equilibrium bid function $b^{L}(\lambda)$ with respect to opportunity cost obtaining

$$
\frac{\partial b^{L}(\lambda)}{\partial(\bar{c}-m)}=-\frac{\partial b^{L}(\lambda)}{\partial m}= \begin{cases}\frac{f_{\lambda}(\lambda) \int_{\lambda}^{\bar{c}}\left[1-F_{\lambda}(x)\right] \mathrm{d} x}{[1-F(\lambda)]^{2}}>0 & \text { if } l<m \\ 0 & \text { otherwise }\end{cases}
$$

Figure 4 assumes uniformly distributed cost pairs $(l, m)$ on $[20,100]^{2}$. It depicts the equilibrium bid functions for option values 0 and 20 corresponding to completion cost values $m=80$ and $m=100$ respectively. The movement from the lower bid function $b^{\mathrm{L}}(l, m=100)$ where there is no opportunity cost to the higher one, $b^{\mathrm{L}}(l, m=80)$ with strictly positive opportunity cost, illustrates how better option values yield less aggressive bids in the first auction.

\subsection{Static SIPV model no special case of dynamic auction model}

Neither the first auction without option value $(m=\bar{c})$ nor the second auction is a special case of the SIPV model. The reason why the bid function $b^{L}(l, m=\bar{c})$ for the first auction with no option value and the SIPV counterpart $b(l)$ do not coincide (Fig. 4) is that the competitor is not informed about unfavorable completion cost for project $M$ and bids less aggressively due to its own option value. Second auction equilibrium bidding with competition is more aggressive than in the SIPV model due to endogenous type selection such that relatively more low-cost types for the second project skip the first auction. This implies for the second auction that any firm expects

Fig. 4 Bidding for project $L$

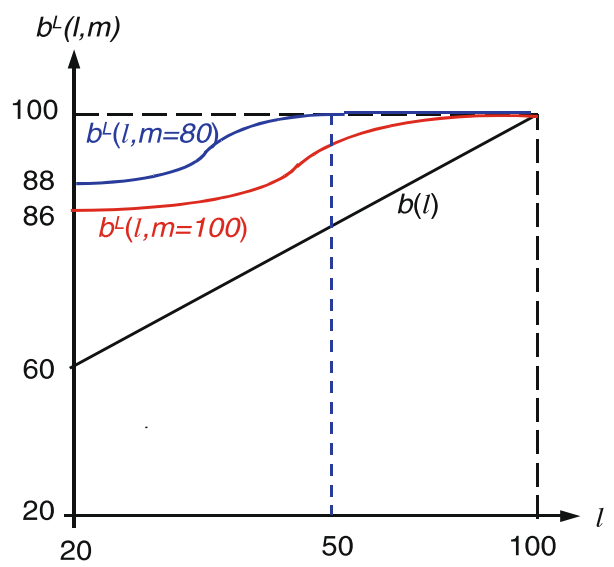


its competitor to face smaller completion costs than in the SIPV model (see Appendix 7.4.2).

The finding of more aggressive bids in the second auction stems from endogenous type selection. This raises the question if it survives if there are other reasons for skipping the first auction. Reserve prices that cap bids at some value $p^{\max }<\bar{c}$ constitute another possibility to generate skipping behavior. Then firms with a large cost type $l \in\left[p^{\max }, \bar{c}\right]$ skip the first auction independent of their option values. In Sect. 5.1 we show that there exists an increasing and concave entry indifference curve $g(m)$ in the presence of reserve prices. By the assumption of uniformly distributed cost, the marginal distribution for project cost $M$ is independent of reserve price $p^{\max }$. Hence, the reason that some cost types skip the first auction because of the reserve price does not affect bidding behavior in the second stage with competition. Instead, the upward sloping entry indifference curve remains the driving factor that implies the selection of relatively more low cost types so that with reserve prices, there still is more competition in the second auction as compared to SIPV bidding.

\subsection{Outside options often but not always imply less aggressive bids than the SIPV model}

The finding that bidding behavior is less aggressive in the first auction of the dynamic model as compared to bidding behavior in the SIPV model holds, e.g., for any bivariate uniform distribution with support $[\underline{c}, \bar{c}]^{2}$ (see Appendix 7.4.1). Interestingly this is not true in general as a counterexample demonstrates. Consider the following bivariate probability density function:

$$
f(l, m)= \begin{cases}\frac{\left(e^{2 l-120}+e^{120-2 l}\right)\left(e^{2 m-120}+e^{120-2 m}\right)}{\left(e^{80}-e^{-80}\right)^{2}}, & \text { if }(l, m) \in[20,100]^{2} \\ 0 & \text { otherwise }\end{cases}
$$

Figure 5 plots the equilibrium bid function of the SIPV model and compares it to the lower bound of bid functions in the first auction of the dynamic model for completion cost values $l \in[20,22]$ for the given distribution. Bid functions for both models intersect at $\hat{l}=21.06$. For project cost values $l<\hat{l}$, bids in the first auction are larger (less aggressive) than in the SIPV model. But for some project cost values $l>\hat{l}$, bids in the first auction are smaller (more aggressive) than in the SIPV model.

To get the intuition for this counterintuitive behavior, consider the SIPV model where a firm bids the expected cost of its competitor given that it submits the lower bid (which is equivalent to having the lower cost type). Suppose now that the competitor is endowed with some option value, transforming the SIPV auction into the first stage of the dynamic model. Again, the firm bids the expected cost of its competitor now including opportunity cost given that it submits the lower bid. Ceteris paribus, the firm's bid increases since all competitor's cost types that have a larger cost in the SIPV model have an even larger cost if the option value is included. However, lower cost types that are ignored by the firm in the SIPV model become larger (opportunity-cost augmented) cost types in the first auction of the dynamic model. 
Fig. 5 Intersecting equilibrium bidding functions

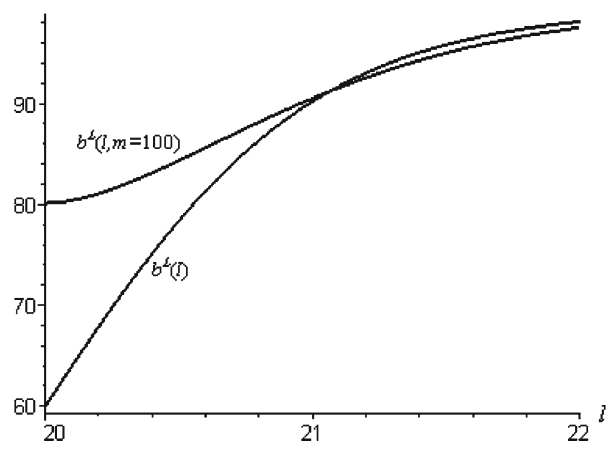

Some of these inflated cost types now exceed the firm's cost value, potentially biasing downwards expected cost given that the firm submits the lower bid. Of course, in the special case where the firm has the lowest cost type in the SIPV model and wins always, there is no ambiguous effect on bids since there are no lower cost types. Thus, for the lowest cost type bidding is always more aggressive in the SIPV model. However, bid functions of the SIPV model and the first auction of the dynamic model may intersect for other cost types leading to the counterintuitive result that some firms may bid more aggressively once faced with a sufficiently small outside option.

\section{Discussion of model extensions}

To address the robustness of our results, we discuss two extensions of our model in this section: reserve prices and weak capacity constraints. In Sect. 5.1, we characterize the symmetric equilibrium with reserve prices in the sense of price caps restricting the set of feasible bids. Since the assumption of strict capacity constraints where each firm has only capacity to complete a single contract is rather strong, we extend the model to allow for weak capacity constraints such that a firm can purchase additional capacity conditional on winning the first auction in Sect. 5.2.

\subsection{Equilibrium with reserve prices}

Let the reserve price in any of the two auctions be given by $p^{\max } \in(\underline{c}, \bar{c})$. Since the reserve price excludes large bids, there is the possibility that a firm skipped the first auction not because of particularly favorable completion cost of the second project, but rather due to extremely unfavorable completion cost of the first project, i.e., $l \geq p^{\max }$. Similarly there are cost types that face no opportunity cost when bidding in the first auction since the completion cost of the second project exceeds the reserve price, $m \geq p^{\max }$. To account for the non-existence of opportunity cost for a subset of cost types, the total cost parameter $\lambda$ has to be redefined appropriately which is discussed next. Subsequently we summarize equilibrium bidding behavior and equilibrium entry behavior. 


\subsubsection{Total cost types for auction $L$ with reserve prices}

With reserve prices the total cost parameter $\lambda$ that gives the completion cost for project $L$ and includes the opportunity cost of winning the first auction is defined as

$$
\lambda \equiv l+\min \left\{0, p^{\max }-m\right\},
$$

where the expression $\min \left\{0, p^{\max }-m\right\}$ captures the option value created by the opportunity to bid in the second auction.

This definition accounts for the fact that it is not worthwhile to bid for project $M$ if completion cost $m$ exceeds the reserve price so that profits are negative if the firm wins the object at the reserve price. Without reserve price, the option value is always non-negative, hence there is no need for the restriction to non-negative values. Figure 6 depicts isoquants for various cost types $\lambda$ in type space. Using the refined definition of $\lambda$, the associated probability density function $f_{\lambda}(\lambda), \lambda \in\left[\underline{c}, \bar{c}+p^{\max }-\underline{c}\right]$, follows as

$$
f_{\lambda}(\lambda)=\int_{\max \left\{\underline{c}, \underline{c}+p^{\max }-\lambda\right\}}^{\min \left\{p^{\max }, \bar{c}+p^{\max }-\lambda\right\}} f\left(\lambda-p^{\max }+m, m\right) \mathrm{d} m+ \begin{cases}\int_{p^{\max }}^{\bar{c}} f(\lambda, m) \mathrm{d} m & \text { if } \lambda \leq \bar{c}, \\ 0 & \text { otherwise. }\end{cases}
$$

\subsubsection{Bidding behavior with reserve prices}

With the refined definition of total cost parameter $\lambda$, equilibrium bidding is straightforward and summarized in the following proposition. Importantly, no firm submits a bid in any auction, if the project completion cost exceeds the reserve price.

Proposition 5 Equilibrium bidding with reserve price $p^{\max } \in(\underline{c}, \bar{c})$

The equilibrium bid functions of a firm with completion cost pair $(l, m) \in[\underline{c}, \bar{c}]^{2}$ are given by:

Fig. 6 Isoquants for $\lambda$ with reserve price $p^{\max }$

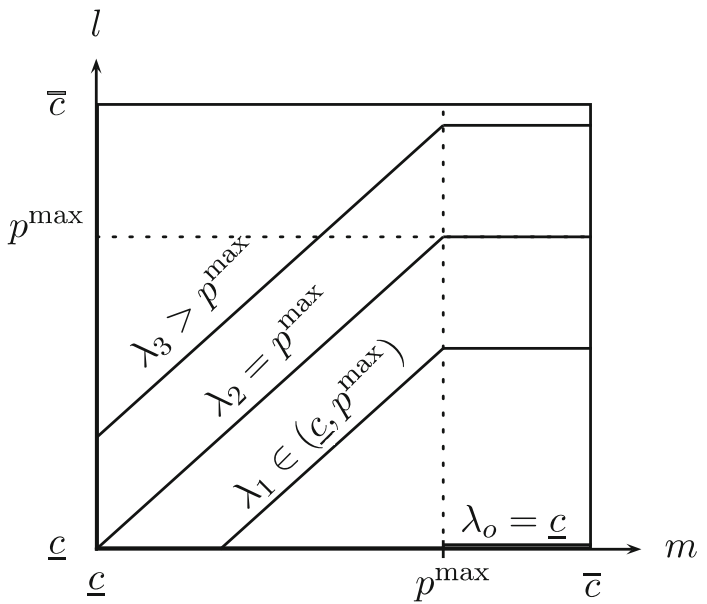


(a) $\quad b^{L}(\lambda)= \begin{cases}p^{\max } & \text { if } l \geq m \\ \lambda+\int_{\lambda}^{p^{\max }}\left[1-F_{\lambda}(x)\right] \mathrm{d} x /\left[1-F_{\lambda}(\lambda)\right] & \text { otherwise }\end{cases}$

if it submits a bid for project $L$ where $\lambda \equiv l+\min \left\{0, p^{\max }-m\right\}$ and $F_{\lambda}(x)=$ $\int_{\underline{c}}^{x} f_{\lambda}(\lambda) \mathrm{d} \lambda$ with $x \in\left[\underline{c}, \bar{c}+p^{\max }-\underline{c}\right]$.

(b) $\quad b^{M}(m)= \begin{cases}p^{\max } & \text { if it is the only bidder } \\ m+\int_{m}^{p^{\max }}\left[1-F_{M \mid \text { skip }}(x)\right] \mathrm{d} x /\left[1-F_{M \mid \text { skip }}(m)\right] & \text { if it is not the only bidder }\end{cases}$ if it submits a bid for project $M$ where $f_{M \mid \text { skip }}(x)=\left[\int_{g(x)}^{\bar{c}} f(l, x) \mathrm{d} l\right] /$ $\left[\int_{\underline{c}}^{\bar{c}} \int_{g(t)}^{\bar{c}} f(l, t) \mathrm{d} l \mathrm{~d} t\right]$ and $F_{M \mid \text { skip }}(x)=\int_{\underline{c}}^{x} f_{M \mid \text { skip }}(s) \mathrm{d} s$ and $g(x)$ denotes the competitor's entry indifference curve; the firm never submits a bid in the second auction if $m \geq p^{\max }$.

Proof The proof is analogous to that with reserve price $p^{\max }=\bar{c}$ and therefore omitted.

\subsubsection{Entry behavior with reserve prices}

Figure 7 illustrates how entry behavior is affected with reserve prices. The qualitative properties illustrated are formally confirmed in Proposition 6. Due to the reserve price, any firm with costs for the first project beyond the reserve, $l \geq p^{\max }$, does not enter the first auction independently of the cost for project $M$. In the figure, these types are indicated by a "rectangular" region spanning from the dotted, horizontal line to the upper bound $\bar{c}$. As in the absence of reserves, there is an increasing entry indifference curve so that not only reserve prices lead some cost types to skip the first auction but also opportunity costs. With reserve prices the entry indifference curve is strictly concave and strictly increasing in $m$ on $\left[\underline{c}, p^{\max }\right]$ and beyond $p^{\max }$.

Proposition 6 For the symmetric perfect Bayesian equilibrium characterized by the representative firm's strategy $\left[b^{L}(l, m), b^{M}(m), \varepsilon(m)\right]$ and the density function $f(l, m)$ :

Fig. 7 Equilibrium entry behavior with reserve prices $p^{\max }<\bar{c}$

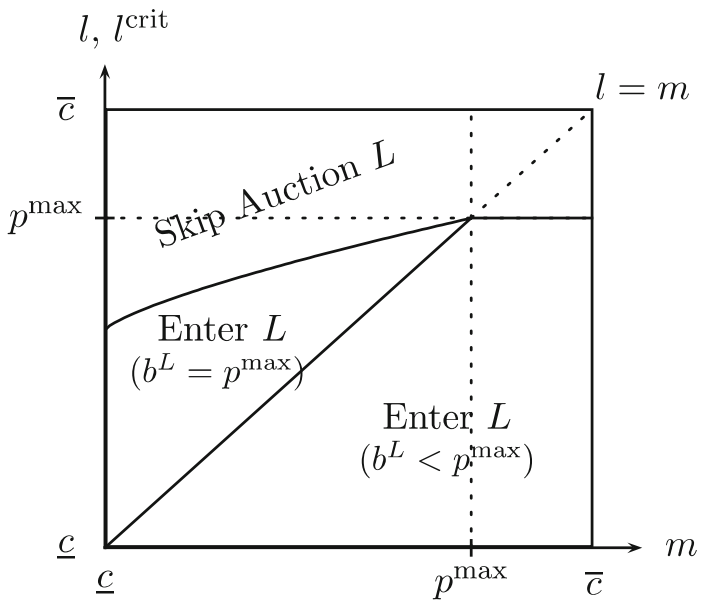


The critical value function $g(m)$ exists and

(i) $m<g(m)<p^{\max }$ if $m \in\left[\underline{c}, p^{\max }\right), g(m)=p^{\max }$ if $m \in\left[p^{\max }, \bar{c}\right], g(\underline{c})>\underline{c}$,

(ii) $g^{\prime}(m)>0$ if $m \in\left[\underline{c}, p^{\max }\right)$,

(iii) $g^{\prime \prime}(m)<0$ if $m \in\left[\underline{c}, p^{\max }\right)$.

Proof The proof is analogous to that with reserve price $\bar{c}$ and therefore omitted.

\subsection{Weak capacity constraints}

In the model, we assumed strong capacity constraints that prevent firms from executing more than one project. This assumption is motivated by empirical evidence suggesting that real-life firms face capacity constraints where our assumption of strong capacity constraints takes this feature to the extreme. Here we relax capacity constraints.

Let firm $i$ have the possibility to buy additional capacity at price $\kappa_{i} \in[0, \bar{c}-\underline{c}]$ to execute a second project after winning the first auction. The case of no capacity constraints, $\kappa_{1}=\kappa_{2}=0$, is well-known since then it emerges a series of two unrelated standard one-shot procurement auctions. If $\kappa_{1}, \kappa_{2} \geq \bar{c}-\underline{c}$, no cost type finds it beneficial to execute more than one project (due to procurers' reserve price of $\bar{c}$ ) and the analysis of our model with strong capacity constraints applies.

Unfortunately, the introduction of weak capacity constraints dwarfs the tractability of the analysis since asymmetric first-price auctions are involved. It is well-known that there are no explicit solutions for asymmetric first-price auctions available except for a few special cases such as the uniform distribution (Plum 1992, see also Maskin and Riley 2000). In fact, this is a reason why the more tractable second-price auction is repeatedly studied in similar sequential auction settings (see, e.g., Katzman 1999, p. 78). As a tribute to these issues and the matter of conciseness, we assume that both project auctions are run in the second-price format and that firm 2 faces no capacity costs at all, $\kappa_{2}=0$, while firm 1 is weakly capacity constrained, $\kappa_{1} \in(0, \bar{c}-\underline{c})$. Next, we investigate if also weak capacity constraints create opportunity costs of auction participation that distort bidding behavior away from one-shot SIPV bidding. Then, we discuss if there are firms that prefer to skip the first auction.

\subsubsection{Deviations from static SIPV bidding}

In this setting, the equilibrium bidding behavior of firm 2 is straightforward. It essentially faces no capacity constraint and regards both auctions as a series of unrelated one-shot auctions. In equilibrium, it adopts the weakly dominant strategy to bid its value of completion cost for each project, see Proposition 7a below.

Firm 1's strategy is more complex. The firm faces a non-trivial entry decision in each auction. To simplify the exposition we interpret a bid equal to the reserve price $\bar{c}$ as the firm's decision not to enter the corresponding auction. Indeed, in this setting if firm 1 bids $\bar{c}$ in any auction, it never wins it since firm 2 submits smaller bids with probability 1 . Firm 1's bid for the first project $L$ is denoted by $b_{1}^{L}$. In case it won the first project, it has to bear the additional capacity cost $\kappa_{1}$ if it also wins the second project. Therefore, its bid for the second project $M$ is conditional on the outcome of the first project. If firm 1 did not win the first project, its bid for project $M$ is denoted 
(a) firm 1 aims to win both projects and it bids $\left(b_{1}^{L}, b_{1}^{M \mid \bar{L}}\right.$ or $\left.b_{1}^{M \mid L}<\bar{c}\right)$

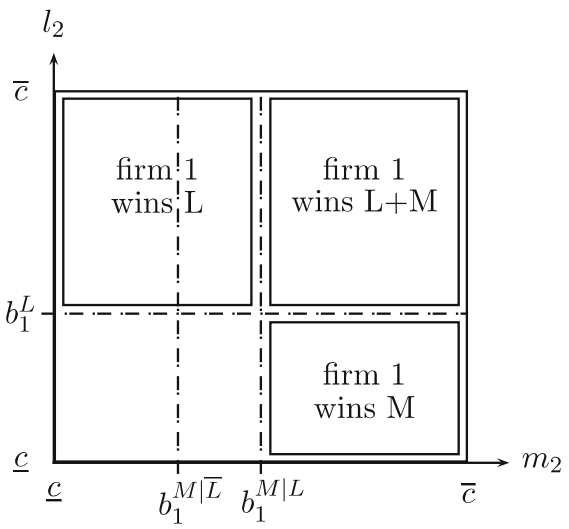

(b) firm 1 aims to win only one project and it bids $\left(b_{1}^{L}, b_{1}^{M \mid \bar{L}}\right.$ or $\left.b_{1}^{M \mid L}=\bar{c}\right)$

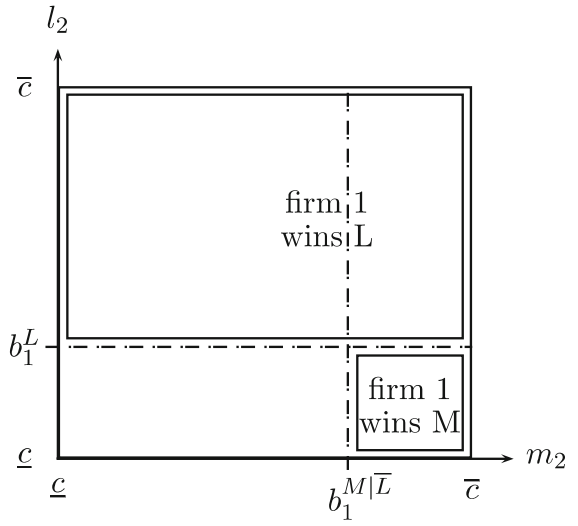

Fig. 8 Firm 2's type and equilibrium bid space together with auction outcomes

by $b_{1}^{M \mid \bar{L}}$ so that it can end up at most with one project. Its bid conditional on winning the first project and possibly ending up with two projects is $b_{1}^{M \mid L}$.

Figure 8 depicts firm 2's type space $[\underline{c}, \bar{c}] \times[\underline{c}, \bar{c}]$. Since firm 2 always bids its completion cost, its type space is equivalent to its space of equilibrium bids. The figure also shows two particular bidding strategies of firm 1. Panel (a) illustrates bidding strategy $\left(b_{1}^{L}, b_{1}^{M \mid \bar{L}}\right.$ or $\left.b_{1}^{M \mid L}<\bar{c}\right)$ where the firm seeks to win both projects so that it possibly incurs the additional capacity cost. Panel (b) shows bidding strategy $\left(b_{1}^{L}, b_{1}^{M \mid \bar{L}}\right.$ or $b_{1}^{M \mid L}=\bar{c}$ ) that ensures not to win both auctions. Moreover, the figure separates firm 2's type space in segments of types that lead firm 1 to win either auction $L$ or $M$, both auctions, or no auction at all. For example, if firm 1's bid for project $L$ is smaller than the bid/type of firm 2 , it wins auction $L$.

Given that firm 2 bids its value of completion costs in each auction, the maximization program of firm 1 is

$$
\begin{aligned}
\max _{\left\{b_{1}^{L}, b_{1}^{M \mid \bar{L}}, b_{1}^{M \mid L}\right\}} \quad \Pi_{1}= & \int_{b_{1}^{L}}^{\bar{c}} \int_{b_{1}^{M \mid L}}^{\bar{c}} f\left(l_{2}, m_{2}\right) \cdot\left(l_{2}+m_{2}-l_{1}-m_{1}-\kappa_{1}\right) \mathrm{d} m_{2} \mathrm{~d} l_{2} \\
& +\int_{b_{1}^{L}}^{{ }^{L}} \int_{\underline{c}}^{b_{1}^{M \mid L}} f\left(l_{2}, m_{2}\right) \cdot\left(l_{2}-l_{1}\right) \mathrm{d} m_{2} \mathrm{~d} l_{2} \\
& +\int_{\underline{c}}^{b_{1}^{L}} \int_{b_{1}^{M \mid \bar{L}}}^{\bar{c}} f\left(l_{2}, m_{2}\right) \cdot\left(m_{2}-m_{1}\right) \mathrm{d} m_{2} \mathrm{~d} l_{2} \\
\text { subject to: } 0 \leq b_{1}^{L}, & b_{1}^{M \mid \bar{L}}, b_{1}^{M \mid L} \leq \bar{c} .
\end{aligned}
$$


The first double integral of the objective function corresponds to the expected payoff accruing to firm 1 if it wins both projects, the second term gives the expected payoff from only winning project $L$, and the third one yields the expected payoff from only winning project $M$. Figure 8 shows how firm 1's bidding strategy $\left(b_{1}^{L}, b_{1}^{M \mid \bar{L}}\right.$ or $\left.b_{1}^{M \mid L}\right)$ relates to expected payoff segments for these events. For $b_{1}^{M \mid L}<\bar{c}$, panel A applies, while panel B illustrates for $b_{1}^{M \mid L}=\bar{c}$, so that firm 1 does not win both projects and, accordingly, the first summand of the objective function drops.

It is straightforward to simplify maximization program (9) with three variables to one with a single variable since the second auction is a one-shot second-price procurement auction where firm 1 knows its completion cost to equal either $m_{1}$ or $m_{1}+\kappa_{1}$. Therefore, firm 1 maximizes its expected payoff by choosing $\beta_{1}^{M \mid \bar{L}}=m_{1}$ and $\beta_{1}^{M \mid L}=\min \left\{m_{1}+\kappa_{1}, \bar{c}\right\}$. The intuition behind $\beta_{1}^{M \mid L}$ is as follows. If firm 1 has already won project 1 , it aims to win the second auction, whenever it benefits from winning it. The expected payoff from also winning the second project is strictly positive whenever its value of completion costs, including the cost for additional capacity, is smaller than the reserve price in the auction, i.e., $m_{1}+\kappa_{1}<\bar{c}$.

Appealing to the Weierstrass theorem, there exists a solution to (9). For expositional convenience, we assume henceforth that completion costs for any firm are independently and identically distributed. Let $f(l, m)=\varphi(l) \cdot \varphi(m)$ where $\varphi(\cdot)$ is a well-defined and differentiable probability density function with support $[\underline{c}, \bar{c}]$ and $\Phi(\cdot)$ denotes the associated cumulative distribution function. Under this assumption, the first-order condition of (9) is necessary and sufficient for a unique maximum $^{19}$

$$
\beta_{1}^{L}\left(l_{1}, m_{1}, \kappa_{1}\right)=\max \left\{l_{1}+\omega_{1}^{L}\left(m_{1}, \kappa_{1}\right), \bar{c}\right\},
$$

where

$$
\begin{aligned}
& \omega_{1}^{L}\left(m_{1}, \kappa_{1}\right) \\
& = \begin{cases}{\left[1-\Phi\left(m_{1}+\kappa_{1}\right)\right] \cdot \kappa_{1}+\int_{m_{1}}^{m_{1}+\kappa_{1}} \varphi\left(m_{2}\right) \cdot\left(m_{2}-m_{1}\right) \mathrm{d} m_{2},} & \text { if } m_{1}+\kappa_{1} \leq \bar{c}, \\
\int_{m_{1}}^{\bar{c}} \varphi\left(m_{2}\right) \cdot\left(m_{2}-m_{1}\right) \mathrm{d} m_{2}, & \text { otherwise. }\end{cases}
\end{aligned}
$$

The bid's mark-up $\omega_{1}^{L}\left(m_{1}, \kappa_{1}\right)$ on project cost $l_{1}$ is strictly positive and reflects the opportunity cost due to bidding for project $L$. It shows two sources of opportunity cost that distort away the weakly capacity constrained firm's bid from its one-shot counterpart $l_{1}$. Firstly, winning auction $L$ possibly leads to additional capacity cost not arising otherwise. To account for that, firms aiming to win both projects include the expected cost of additional capacity in their bid. The expected equilibrium cost of additional capacity with bid $m_{1}+\kappa_{1}$ is the product of the probability of winning auction $M,\left[1-\Phi\left(m_{1}+\kappa_{1}\right)\right]$, and the cost of additional capacity, $\kappa_{1}$. Secondly, winning auction $L$ decreases the probability of winning auction $M$ since the optimal bid for

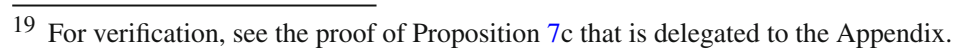


project $M$ increases by $\kappa_{1}$ if firm 1 wins auction $L$. It follows that winning project $L$ prevents firm 1 to win against any cost type of firm 2 such that $m_{2} \in\left[m_{1}, m_{1}+\kappa_{1}\right]$. The resulting loss of expected payoff is included in the profit-maximizing bid for auction $L$ and reflects in the integral expression of $\omega_{1}^{L}\left(m_{1}, \kappa_{1}\right)$. Note that we have $\omega_{1}^{L}\left(m_{1}, \kappa_{1}\right)<\bar{c}-\underline{c}^{20}$

Proposition 7 Equilibrium bidding with weak capacity constraints

(a) Equilibrium bid functions of (unconstrained) firm 2 in auctions L and M:

$$
\begin{aligned}
& \beta_{2}^{L}\left(l_{2}\right)=l_{2}, \\
& \beta_{2}^{M}\left(m_{2}\right)=m_{2} .
\end{aligned}
$$

(b) Equilibrium bid function of firm 1 in auction $M$ :

$$
\beta_{1}^{M}\left(m_{1}\right)= \begin{cases}m_{1}, & \text { if it did not win project } L \\ m_{1}+\kappa_{1}, & \text { if it won project L and } m_{1}+\kappa_{1}<\bar{c} \\ \bar{c}, & \text { otherwise. }\end{cases}
$$

(c) Equilibrium bid function of firm 1 in auction L:

$$
\beta_{1}^{L}\left(l_{1}, m_{1}, \kappa_{1}\right)=\max \left\{l_{1}+\omega_{1}^{L}\left(m_{1}, \kappa_{1}\right), \bar{c}\right\},
$$

where $\omega_{1}^{L}\left(m_{1}, \kappa_{1}\right)$ is given in the main text preceding the proposition.

Proof The proof is delegated to Appendix 7.5.

\subsubsection{Entry behavior}

With firm 2 submitting bids always smaller than the reserve price, the decision of firm 1 to enter or to skip the first auction is equivalent to that of submitting a bid that is either smaller than or equal to the reserve price. In the latter case it does not win auction $L$ with probability 1 . We interpret this type of bidding behavior as skipping auction $L$.

Therefore, the decision to enter or to skip auction $L$ is embedded in firm 1's maximization program (9). To see this, consider the objective function in (9). Bid $b_{1}^{L}=\bar{c}$ eliminates the first and the second line of the objective function that represent expected payoffs in case of either only winning auction $L$ or winning both auctions. Only the third line of the objective function remains. It precisely gives the expected payoff if firm 1 does not enter the first auction. Accordingly, the set of cost types that lead firm 1 to skip auction $L, G_{1}$, is given by all cost pairs that imply an equilibrium bid of $\bar{c}$ for project $L: G_{1}=\left\{\left(l_{1}, m_{1}\right) \in[\underline{c}, \bar{c}]^{2} \mid \beta_{1}^{L}\left(l_{1}, m_{1}, \kappa_{1}\right)=\bar{c}\right\}$.

Intuitively, the set of firms that skip the first auction is non-empty since a firm with maximum cost to complete the first project but more favorable cost for executing the second project, $\left(l_{1}=\bar{c}, m_{1}<\bar{c}\right)$, faces a zero payoff from entering the first auction

$\overline{20}$ By definition $\kappa_{1}<\bar{c}-\underline{c}$. Furthermore, $m_{2}-m_{1}<\bar{c}-\underline{c}$ if $m_{2}<\bar{c}$ and $m_{2}-m_{1} \leq \bar{c}-\underline{c}$ if $m_{2}=\bar{c}$. 
Fig. 9 Equilibrium entry behavior of firm 1

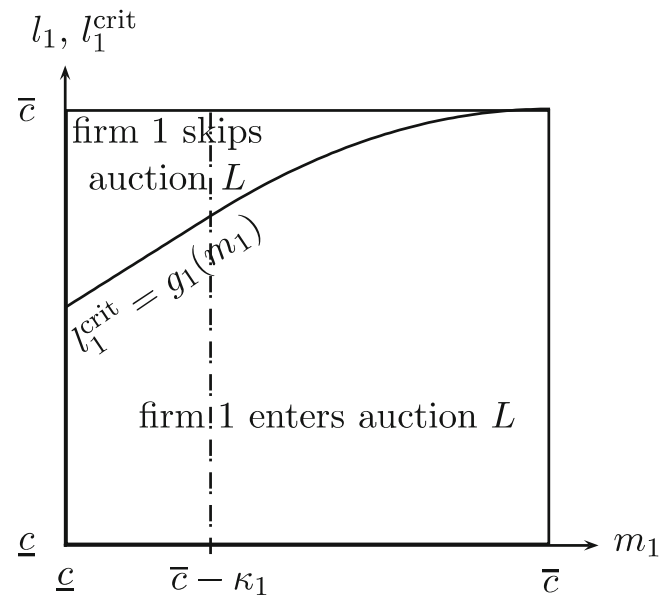

while entering the second auction leads to a strictly positive expected payoff. Figure 9 illustrates the set of cost types that lead firm 1 to skip the first auction. Again, firm 1 's equilibrium separatrix of entry behavior is denoted by $g_{1}\left(m_{1}\right)$. Its properties are summarized in Proposition 8.

Proposition 8 In equilibrium, the separatrix of entry behavior $l_{1}^{\text {crit }}=g_{1}\left(m_{1}\right)$ is given by

$$
g_{1}\left(m_{1}\right)=\bar{c}-\omega_{1}^{L}\left(m_{1}, \kappa_{1}\right)
$$

with properties

(a) $\underline{c}<g_{1}\left(m_{1}\right)<\bar{c}$ if $m_{1} \in[\underline{c}, \bar{c})$ and $g_{1}(\bar{c})=\bar{c}$,

(b) $g_{1}^{\prime}\left(m_{1}\right)>0$,

(c) $g_{1}^{\prime \prime}\left(m_{1}\right)<0$ if $m_{1} \in\left[\bar{c}-\kappa_{1}, \bar{c}\right]$.

Proof The proof is delegated to Appendix 7.6.

Note that the entry separatrix $g_{1}\left(m_{1}\right)$ does not coincide with the entry indifference curve that is defined by the equality of expected payoffs from entering and skipping auction $L$. In this model, the entry indifference curve is given by set $G_{1}$ due to the fact that the submission of bid $\bar{c}$ leads to identical expected payoffs from skipping auction $L$ and participating in auction $L$ with bid $\bar{c}$.

\section{Concluding remarks}

Motivated by recent empirical evidence that suggests that (1) firms perceive independent one-shot procurement auctions not in isolation but rather as an auction sequence, that (2) subcontracting is imperfect and that (3) firms are aware of their opportunity cost, this paper introduced a sequential procurement auction model to study firms' 
first-price equilibrium bidding strategies. Our model incorporates a sequence of two auctions with two capacity constrained bidders. In contrast to a procurement auction version of Weber (1983), the presented model predicts that firms not always participate in the first auction. We explicitly derive a firm's entry indifference curve for the first auction, depending on the projects' relative completion costs. Endogenous participation in our model may lead to both bidders skipping the first auction. Even though there is full competition in the second auction first-price equilibrium bidding is affected as skipping reveals information on the competitor's type. In addition bidding behavior in each auction stage strongly depends on the option value that a firm places on remaining auctions contrasting with a procurement auction version of the standard SIPV model. Pivotal for the first auction's competitive bids is a firm's completion cost for the first project augmented by the option value from the opportunity to participate in the second auction. First auction equilibrium bids are increasing in this option value.

We demonstrate that our results on entry and bidding behavior do not critically depend on our stylized model assumptions of bidders each having capacity to complete a single contract. With strong capacity constraints winning the first auction precludes participating in the second auction. If firms participate in the first auction they shade their bids according to the option value resulting from the subsequent auction. This effect still shows up if firms face weak capacity constraints in the sense that they can buy additional capacity to execute the second project conditional on winning the first contract. Intuitively, then the option value occurs as winning the first contract reduces the probability of winning the second contract due to the cost of buying additional capacity.

As procurement contracts are usually auctioned in first-price auctions we were interested in the first-price equilibrium and its implications in the first place. Furthermore, we prove revenue equivalence for the dynamic model with heterogeneous objects. Revenue equivalence has two main implications: First, the equilibrium entry decision for the first auction does not depend on the auction design and second, the results on price trends derived by Gale and Hausch (1994) assuming second-price auctions do also apply to our model.

If real-world firms regard auction stages in a sequence of auctions as one-shot games and, thus, ignore alternative transaction opportunities, the focus on the standard SIPV model is appropriate. The experimental data, however, generated by the implementation of our procurement auction model in the laboratory, see Brosig and Reiß (2007), suggest that the option value of alternative transaction opportunities strongly influences bidding and entry behavior in the lab similarly to the theoretical predictions and renders our approach relevant.

\section{Appendix}

\subsection{Proof of lemma 2}

Noting that $m_{1}$ and $b_{1}^{M}$ are constants and substitution for the latter according to Proposition 1 leads to 


$$
\begin{aligned}
& \frac{\int_{m_{1}}^{\bar{c}}\left[1-F_{M_{2} \mid \text { skip }}(x)\right] \mathrm{d} x}{1-F_{M_{2} \mid \text { skip }}\left(m_{1}\right)} \cdot \int_{m_{1}}^{\bar{c}} \int_{g_{2}\left(m_{2}\right)}^{\bar{c}} f\left(l_{2}, m_{2}\right) \mathrm{d} l_{2} \mathrm{~d} m_{2} \\
& =\int_{m_{1}}^{\bar{c}}\left(m_{2}-m_{1}\right) \int_{g_{2}\left(m_{2}\right)}^{\bar{c}} f\left(l_{2}, m_{2}\right) \mathrm{d} l_{2} \mathrm{~d} m_{2} .
\end{aligned}
$$

Since $1-F_{M_{2} \mid \operatorname{skip}}(x)=\left[\int_{x}^{\bar{c}} \int_{g_{2}(s)}^{\bar{c}} f\left(l_{2}, s\right) \mathrm{d} l_{2} \mathrm{~d} s\right] /\left[\int_{\underline{c}}^{\bar{c}} \int_{g_{2}(t)}^{\bar{c}} f\left(l_{2}, t\right) \mathrm{d} l_{2} \mathrm{~d} t\right]$ we obtain from the last equation

$$
\int_{m_{1}}^{\bar{c}} \int_{x}^{\bar{c}} \int_{g_{2}(s)}^{\bar{c}} f\left(l_{2}, s\right) \mathrm{d} l_{2} \mathrm{~d} s \mathrm{~d} x=\int_{m_{1}}^{\bar{c}}\left(m_{2}-m_{1}\right) \int_{g_{2}\left(m_{2}\right)}^{\bar{c}} f\left(l_{2}, m_{2}\right) \mathrm{d} l_{2} \mathrm{~d} m_{2} .
$$

Let $\phi\left(m_{2}\right)$ be the integral of $\int_{g_{2}\left(m_{2}\right)}^{\bar{c}} f\left(l_{2}, m_{2}\right) \mathrm{d} l_{2}$, then integration by parts of the right-hand side using $\iint_{g_{2}\left(m_{2}\right)}^{\bar{c}} f\left(l_{2}, m_{2}\right) \mathrm{d} l_{2} \mathrm{~d} m_{2}=\phi(\bar{c})-\int_{m_{2}}^{\bar{c}} \int_{g_{2}(u)}^{\bar{c}} f\left(l_{2}, u\right) \mathrm{d} l_{2} \mathrm{~d} u$ leads to

$$
\int_{m_{1}} \int_{x}^{\bar{c}} \int_{g_{2}(s)}^{\bar{c}} f\left(l_{2}, s\right) \mathrm{d} l_{2} \mathrm{~d} s \mathrm{~d} x=\int_{m_{1}}^{\bar{c}} \int_{m_{2}}^{\bar{c}} \int_{g_{2}(s)}^{\bar{c}} f\left(l_{2}, s\right) \mathrm{d} l_{2} \mathrm{~d} s \mathrm{~d} m_{2}
$$

which obviously holds.

\subsection{Proof of Lemma 3}

Suppose $g_{1}\left(m_{1}\right)=\bar{c}$, then firm 1 always enters auction $L$. For $l_{1}=\bar{c}$, the firm never makes any profit from project $L$ such that the strategy to enter auction $L$ and continuing bidding in auction $M$ if possible is profitable only if it does not win project $L$ resulting in the same profit as if the firm had skipped auction $L$. If the competitor has a cost advantage for project $M$, it either bids $\bar{c}$ for project $L$ or skips the auction. In both cases, firm 1 wins project $L$ with positive probability although it could have won the profitable auction $M$ in some cases since $m_{1}<\bar{c}$ such that $E\left[\Pi_{1}^{L+M} \mid\left(l_{1}=\bar{c}, m_{1}<\bar{c}\right)\right]<E\left[\Pi_{1}^{M} \mid m_{1}<\bar{c}\right]$. Since $g_{1}\left(m_{1}\right)>\bar{c}$ leads to the same entry strategy as $g_{1}\left(m_{1}\right)=\bar{c}$ implies, it follows that $g_{1}\left(m_{1}\right)<\bar{c}$ for $m_{1} \in[\underline{c}, \bar{c})$.

For $g_{1}\left(m_{1}\right)<\bar{c}$ it follows immediately from (5) that $E\left[\Pi_{1}^{M} \mid m_{1}<\bar{c}\right]<\bar{c}-m_{1}$. If firm 1 has no cost advantage for project $M$, i.e., $l_{1} \leq m_{1}$, according to Proposition 1 its bidding behavior guarantees it at least profit $\bar{c}-m_{1}$ for each feasible completion cost pair of its competitor, thus $E\left[\Pi_{1}^{L+M} \mid l_{1} \leq m_{1}<\bar{c}\right] \geq \bar{c}-m_{1}$. Therefore, $g_{1}\left(m_{1}\right)>m_{1}, m_{1} \in[\underline{c}, \bar{c})$.

If $m_{1}=\bar{c}$, then the definition of $g_{1}\left(m_{1}\right)$ directly implies $g_{1}(\bar{c})=\bar{c}$. To see this note that $\left.E\left[\Pi_{1}^{M} \mid m_{1}=\bar{c}\right)\right]=0$ and $E\left[\Pi_{1}^{L+M} \mid(\bar{c}, \bar{c})\right]=0$ while $E\left[\Pi_{1}^{L+M} \mid\left(l_{1}<\bar{c}, \bar{c}\right)\right]>0$ which completes the proof. 


\subsection{Proof of Proposition 2}

In order to determine the entry indifference curve $l_{1}^{\text {crit }}=g_{1}\left(m_{1}\right)$ it is sufficient to consider entry condition (1) for firms with a cost advantage for project $M$ since, according to Lemma 3, for all other types expected profits strictly exceed opportunity costs. Thus, substitution of the definitions of expected profits from both entry strategies into (4) leads with some minor algebraic manipulations using the properties of $f(l, m)$ to the implicit definition of the entry indifference curve $l_{1}^{\text {crit }}=$ $g\left(m_{1}\right)$ :

$$
\begin{aligned}
& \frac{\bar{c}-m_{1}}{2}+\frac{2 \bar{c}-\left(l_{1}^{\text {crit }}+m_{1}\right)}{2}\left[\frac{1}{2}-\int_{\underline{c}}^{\bar{c}} \int_{g_{2}\left(m_{2}\right)}^{\bar{c}} f\left(l_{2}, m_{2}\right) \mathrm{d} l_{2} \mathrm{~d} m_{2}\right] \\
& +\left(\bar{c}-l_{1}^{\text {crit }}\right) \int_{\underline{c}}^{\bar{c}} \int_{g_{2}\left(m_{2}\right)}^{\bar{c}} f\left(l_{2}, m_{2}\right) \mathrm{d} l_{2} \mathrm{~d} m_{2} \\
& -\left(\bar{c}-m_{1}\right) \int_{\underline{c}}^{g_{2}} \int_{\underline{c}}^{g_{2}\left(m_{2}\right)} f\left(l_{2}, m_{2}\right) \mathrm{d} l_{2} \mathrm{~d} m_{2} \\
& -\int_{m_{1}}^{\int_{g_{2}\left(m_{2}\right)}^{c}} \int_{\left(m_{2}-m_{1}\right) \cdot f\left(l_{2}, m_{2}\right) \mathrm{d} l_{2} \mathrm{~d} m_{2}=0 .}^{\bar{c}}
\end{aligned}
$$

Part (b) of the proposition directly implies the existence and the claimed properties of set $G$ in (a). Therefore it is sufficient to show the existence of $g(m)$ satisfying (i)-(iii) to prove the proposition.

To prove existence we show that Eq. (11) is satisfied for any $m_{1} \in[\underline{c}, \bar{c}]$ by some unique $l_{1}^{\text {crit }} \in\left[m_{1}, \bar{c}\right]$. For $m_{1}=\bar{c}$ Eq. (11) is satisfied by $l_{1}^{\text {crit }}=\bar{c}$ while any other value of $l_{1}^{\text {crit }}<\bar{c}$ yields a strictly positive left-hand side. ${ }^{21}$ Next consider any $m_{1} \in[\underline{c}, \bar{c})$ and refer to the left-hand side of Eq. (11) as $h\left(l_{1}^{\text {crit }}, m_{1}\right)$. It is straightforward that $h($.) is differentiable and therefore continuous in both of its arguments, particularly in $l_{1}^{\text {crit }}$.

21 With $m_{1}=\bar{c}$, the left-hand side of Eq. (11) reduces to the following two terms:

$$
\frac{\bar{c}-l_{1}^{\text {crit }}}{2}\left[\frac{1}{2}-\int_{\underline{c}}^{\bar{c}} \int_{g_{2}\left(m_{2}\right)}^{\bar{c}} f\left(l_{2}, m_{2}\right) \mathrm{d} l_{2} \mathrm{~d} m_{2}\right]+\left(\bar{c}-l_{1}^{\text {crit }}\right) \int_{\underline{c}}^{\bar{c}} \int_{g_{2}\left(m_{2}\right)}^{\bar{c}} f\left(l_{2}, m_{2}\right) \mathrm{d} l_{2} \mathrm{~d} m_{2} .
$$

Each factor in this expression is strictly positive for any $l_{1}^{\text {crit }}<\bar{c}$. To see this, note that the first double integral is strictly smaller than $1 / 2$ by the boundary properties of the entry indifference curve, see Lemma 3 . 
Further $h($.$) is strictly monotonic decreasing in l_{1}^{\text {crit }}$ :

$$
\frac{\partial h\left(l_{1}^{\text {crit }}, m_{1}\right)}{\partial l_{1}^{\text {crit }}}=-\frac{1}{4}-\frac{1}{2}\left[\int_{\underline{c}}^{\bar{c}} \int_{g_{2}\left(m_{2}\right)}^{\bar{c}} f\left(l_{2}, m_{2}\right) \mathrm{d} l_{2} \mathrm{~d} m_{2}\right]<0 .
$$

Since $h($.$) is continuous and strictly downward-sloping in l_{1}^{\text {crit }}$, the intermediate value theorem implies a unique solution to $h\left(l_{1}^{\text {crit }}, m_{1}<\bar{c}\right)=0$, and equivalently to Eq. (11), if $h\left(l_{1}^{\text {crit }}=m_{1}, m_{1}<\bar{c}\right)>0$ and $h\left(l_{1}^{\text {crit }}=\bar{c}, m_{1}<\bar{c}\right)<0$ which we establish in the following:

- $h\left(l_{1}^{\text {crit }}=m_{1}, m_{1}<\bar{c}\right)>0$

Substituting $m_{1}$ for $l_{1}^{\text {crit }}$ in $h($.$) leads to:$

$$
\begin{aligned}
h\left(m_{1}, m_{1}\right)= & \bar{c}-m_{1}-\left(\bar{c}-m_{1}\right) \int_{\underline{c}}^{\bar{c}} \int_{\underline{c}}^{g_{2}\left(m_{2}\right)} f\left(l_{2}, m_{2}\right) \mathrm{d} l_{2} \mathrm{~d} m_{2} \\
& -\int_{m_{1}}^{\bar{c}} \int_{g_{2}\left(m_{2}\right)}^{\bar{c}}\left(m_{2}-m_{1}\right) f\left(l_{2}, m_{2}\right) \mathrm{d} l_{2} \mathrm{~d} m_{2} .
\end{aligned}
$$

By

$$
\bar{c}-m_{1} \geq\left(\bar{c}-m_{1}\right)\left[\int_{\underline{c}}^{\bar{c}} \int_{\underline{c}}^{g_{2}\left(m_{2}\right)} f\left(l_{2}, m_{2}\right) \mathrm{d} l_{2} \mathrm{~d} m_{2}+\int_{m_{1}}^{\bar{c}} \int_{g_{2}\left(m_{2}\right)}^{\bar{c}} f\left(l_{2}, m_{2}\right) \mathrm{d} l_{2} \mathrm{~d} m_{2}\right],
$$

we have $h\left(m_{1}, m_{1}\right)>0$.

- $h\left(l_{1}^{\text {crit }}=\bar{c}, m_{1}<\bar{c}\right)<0$

Substituting $\bar{c}$ for $l_{1}^{\text {crit }}$ in $h($.$) yields$

$$
\begin{aligned}
h\left(\bar{c}, m_{1}\right)= & \frac{3}{4}\left(\bar{c}-m_{1}\right)-\frac{\bar{c}-m_{1}}{2}(A+B)-\frac{\bar{c}-m_{1}}{2} B \\
& -\int_{m_{1}}^{\bar{c}} \int_{g_{2}\left(m_{2}\right)}^{\bar{c}}\left(m_{2}-m_{1}\right) f\left(l_{2}, m_{2}\right) \mathrm{d} l_{2} \mathrm{~d} m_{2},
\end{aligned}
$$

where

$$
\begin{aligned}
A & \equiv \int_{\underline{c}}^{\bar{c}} \int_{g_{2}\left(m_{2}\right)}^{\bar{c}} f\left(l_{2}, m_{2}\right) \mathrm{d} l_{2} \mathrm{~d} m_{2}, \\
B & \equiv \int_{\underline{c}}^{\bar{c}} \int_{\underline{c}}^{g_{2}\left(m_{2}\right)} f\left(l_{2}, m_{2}\right) \mathrm{d} l_{2} \mathrm{~d} m_{2},
\end{aligned}
$$


and by definition of the probability density function

$$
A+B \equiv 1 .
$$

By the boundary properties (Lemma 3) together with the distribution's assumption of stochastic equivalence, we have $B>\frac{1}{2} \cdot{ }^{22}$ It follows that

$$
\frac{3}{4}<\frac{1}{2}+\frac{1}{2} B
$$

implying $h\left(\bar{c}, m_{1}\right)<0$.

The existence of the entry indifference curve together with continuous differentiability of (11) in $l_{1}^{\text {crit }}$ and $m_{1}$ implies via the implicit function theorem continuous differentiability of $l_{1}^{\text {crit }}=g_{1}\left(m_{1}\right)$ as defined by (11) for any function $g_{2}\left(m_{2}\right)$. In a symmetric equilibrium, both firms act in accordance with the same equilibrium entry indifference curve denoted by $g(m)$. Thus $g_{1}(m)=g_{2}(m)=g(m)$ and (i) follows from Lemma 3. Again, using symmetry of equilibrium entry behavior with identity (11) and subsequent differentiation w.r.t. $m$ leads to

$$
\begin{aligned}
& -\frac{g^{\prime}(m)}{2} \int_{\underline{c}}^{\bar{c}} \int_{g\left(m_{2}\right)}^{\bar{c}} f\left(l_{2}, m_{2}\right) \mathrm{d} l_{2} \mathrm{~d} m_{2}-\frac{g^{\prime}(m)}{4} \\
& +\frac{1}{4}-\frac{1}{2} \int_{\underline{c}}^{\bar{c}} \int_{g\left(m_{2}\right)}^{\bar{c}} f\left(l_{2}, m_{2}\right) \mathrm{d} l_{2} \mathrm{~d} m_{2} \\
& +\int_{m} \int_{g\left(m_{2}\right)}^{\bar{c}} f\left(l_{2}, m_{2}\right) \mathrm{d} l_{2} \mathrm{~d} m_{2}=0 .
\end{aligned}
$$

By (i) $\int_{\underline{c}}^{\bar{c}} \int_{g\left(m_{2}\right)}^{\bar{c}} f\left(l_{2}, m_{2}\right) \mathrm{d} l_{2} \mathrm{~d} m_{2}<\int_{\underline{c}}^{\bar{c}} \int_{m_{2}}^{\bar{c}} f\left(l_{2}, m_{2}\right) \mathrm{d} l_{2} \mathrm{~d} m_{2}$ where the latter equals $1 / 2$, identity (13) implies $g^{\prime}(m)>0$ as claimed in (ii).

Differentiation of (13) w.r.t. $m$ yields

$$
-\frac{g^{\prime \prime}(m)}{2} \int_{\underline{c}}^{\bar{c}} \int_{g\left(m_{2}\right)}^{\bar{c}} f\left(l_{2}, m_{2}\right) \mathrm{d} l_{2} \mathrm{~d} m_{2}-\frac{g^{\prime \prime}(m)}{4}-\int_{g(m)}^{\bar{c}} f\left(l_{2}, m\right) \mathrm{d} l_{2}=0
$$

implying (iii).

\footnotetext{
22 To see this intuitively, recall that Lemma 3 asserts that the entry indifference curve lies above the $45^{\circ}$ line in type space and that stochastic equivalence implies the probability of a cost type above the $45^{\circ}$ line, $l_{1}>m_{1}$, to be $1 / 2$.
} 
7.4 Comparative statics under the uniform distribution

\subsubsection{Bidding in the first auction is less aggressive than in the static SIPV model}

We show that the difference between the bid function of our dynamic model for the first auction and the bid function of the static SIPV model is positive for any bivariate uniform distribution with pdf $f(l, m)=1 /(\bar{c}-\underline{c})^{2} \forall(l, m) \in[\underline{c}, \bar{c}]^{2} \subseteq R_{+}^{2}$. Since there exists a continuum of bid functions for project $L$ depending on the particular realization of the cost parameter for the second project, $m$, and bids decrease in $m$ by (8), it is sufficient to show that the difference is positive for the largest cost parameter $m=\bar{c}$, i.e.,

$$
\Delta(l) \equiv b^{L}(l, m=\bar{c})-b(l)>0, \quad l \in[\underline{c}, \bar{c}),
$$

where equilibrium bid functions are defined in Proposition 1 and Lemma 1. The pdf in the static SIPV model is given by the marginal density function of the bivariate uniform distribution with respect to $L$, i.e., $h(l) \equiv \int_{c}^{\bar{c}} f(l, m) \mathrm{d} m$. Clearly, $\Delta(l=\bar{c})=0$. Since firms with a cost advantage for the second project, $l \geq m$, submit the largest feasible bid $\bar{c}$ in the auction for project $L$ and bids always fall below $\bar{c}$ in the SIPV model, $b(l<\bar{c})<\bar{c}$, it is sufficient to focus on firms with a cost advantage for the first project, i.e., $l<m$. Then, the difference in equilibrium bids is given by

$$
\Delta(l)=\int_{l}^{\bar{c}}\left[1-F_{\lambda}(x)\right] \mathrm{d} x /\left[1-F_{\lambda}(l)\right]-\int_{l}^{\bar{c}}[1-H(x)] \mathrm{d} x /[1-H(l)]
$$

recalling that $\lambda \equiv l+\bar{c}-m$. Here, the particular cdfs are $F_{\lambda}(x)=(x-\underline{c})^{2} / 2(\bar{c}-\underline{c})^{2}$, $x \in[\underline{c}, \bar{c}]$, and $H(x)=(x-\underline{c}) /(\bar{c}-\underline{c}), x \in[\underline{c}, \bar{c}]$. Integrating and rearranging leads to

$$
\begin{aligned}
\Delta(l) & =\frac{1}{6}(\bar{c}-l) \frac{A_{1}}{A_{2}}, \\
A_{1} & =4 \bar{c}^{2}-2 \bar{c} l-6 \bar{c} \underline{c}+l^{2}+3 \underline{c^{2}}, \\
A_{2} & =2 \bar{c}^{2}-4 \bar{c} \underline{c}+\underline{c}^{2}-l^{2}+2 \underline{c} l .
\end{aligned}
$$

Note that $A_{1}$ and $A_{2}$ are always positive and monotone decreasing since $A_{1}(l=\underline{c})=$ $4(\bar{c}-\underline{c})^{2}, A_{1}(l=\bar{c})=3(\bar{c}-\underline{c})^{2}$, and $\partial A_{1} / \partial l=2(l-\bar{c}) ; A_{2}(l=\underline{c})=$ $2(\bar{c}-\underline{c})^{2}, A_{2}(l=\bar{c})=(\bar{c}-\underline{c})^{2}$, and $\partial A_{2} / \partial l=2(\underline{c}-l)$. This confirms that $\Delta(l)>0$ $\forall l \in[\underline{\mathrm{c}}, \bar{c})$.

\subsubsection{Bidding in the second auction with competition is more aggressive than in the static SIPV model}

Analogously to the preceding subsection, we show that the difference between the bid function of our dynamic model for the second auction and the bid function of the 
static SIPV model is negative for any bivariate uniform distribution. Here, the bidding difference is defined by

$$
\begin{aligned}
\Delta(m) \equiv & \int_{m}^{\bar{c}}\left[1-F_{M \mid \text { skip }}(x)\right] \mathrm{d} x /\left[1-F_{M \mid \text { skip }}(m)\right] \\
& -\int_{m}^{\bar{c}}[1-H(x)] \mathrm{d} x /[1-H(m)], \quad m \in[\underline{c}, \bar{c}),
\end{aligned}
$$

where $F_{M \mid \text { skip }}(x)$ is defined in Proposition 1 and $H(x)$ is given above. Again $\Delta$ $(m=\bar{c})=0$. Using the distributions under the uniformity assumption and rearranging leads to

$$
\Delta(m)=\frac{-\int_{m}^{\bar{c}} \int_{x}^{\bar{c}} g(s) \mathrm{d} s \mathrm{~d} x+\frac{\bar{c}-m}{2} \int_{m}^{\bar{c}} g(s) \mathrm{d} s}{\int_{m}^{\bar{c}}[\bar{c}-g(s)] \mathrm{d} s} .
$$

Since the denominator is strictly positive for any $m \in[\underline{c}, \bar{c})$, Proposition $2 \mathrm{~b}(\mathrm{i})$, it is sufficient to show that the numerator is strictly negative. Using the fact that $(\bar{c}-m) / 2 \int_{m}^{\bar{c}} g(s) \mathrm{d} s=1 / 2 \int_{m}^{\bar{c}} \int_{x}^{\bar{c}} g(s) \mathrm{d} s \mathrm{~d} x+1 / 2 \int_{m}^{\bar{c}} \int_{m}^{x} g(s) \mathrm{d} s \mathrm{~d} x, \Delta(m)<0$ $\forall m \in[\underline{c}, \bar{c})$ if

$$
\int_{m}^{\bar{c}} \int_{x}^{\bar{c}} g(s) \mathrm{d} s \mathrm{~d} x-\int_{m}^{\bar{c}} \int_{m}^{x} g(s) \mathrm{d} s \mathrm{~d} x>0 .
$$

Notice that the integral on the left side is equivalent to $\int_{m}^{\bar{c}} \int_{\bar{c}-x+m}^{\bar{c}} g(s) \mathrm{d} s \mathrm{~d} x$ changing the direction of integration. Rewriting (14) leads to

$$
\int_{m}^{\bar{c}}\left[\int_{m}^{x} g(s+\bar{c}-x)-\int_{m}^{x} g(s) \mathrm{d} s\right] \mathrm{d} x>0 .
$$

Since the entry indifference curve $g(\cdot)$ is strictly increasing, Proposition $2 \mathrm{~b}(\mathrm{ii}), \bar{c}-x>$ $0 \forall x \in(m, \bar{c})$, and the inner integrals cancel at $m$ and $\bar{c}$, the inequality always holds for $m \in[\underline{c}, \bar{c})$.

\subsection{Proof of proposition 7 (equilibrium bid functions)}

Proof (a) and (b) Independently of the outcome of the first auction for project $L$, the auction for project $M$ can be viewed as a standard one-shot second-price auction. We are interested in an equilibrium where firms employ weakly dominant actions whenever available. ${ }^{23}$ Clearly, firms 1 and 2 bid their values of completion costs in

\footnotetext{
${ }^{23}$ For other, yet unconvincing, equilibria in a one-shot second-price auction, see Blume and Heidhues (2004). The spirit of asymmetric equilibria discussed there can be used to generate multiple equilibria in our context.
} 
auction $M$. Firm 2 (facing no capacity constraints) bids $m_{2}$ and firm 1 bids $m_{1}$ if it did not win project $L$ previously. If it won project $L$, its cost of completing project $M$ increases to $m_{1}+\kappa_{1}$. If this value exceeds reserve price $\bar{c}$, firm 1 bids $\bar{c}$ that ensures losing auction $M$. Bidding $\bar{c}$ can be interpreted as not participating in the auction since firm 2 always bids below (except if $m_{2}=\bar{c}$ occurring with probability zero). Finally, (unconstrained) firm 2 views the first auction as independent of the second one since winning or not winning project $L$ does not affect its completion cost for project $M$, so that it bids its value of completion cost $l_{2}$ in auction $L$.

(c) We differentiate objective function (9) with respect to choice variable $b_{1}^{L}$, noting that the predetermined optimal solutions $b_{1}^{*^{M \mid \bar{L}}}=m_{1}$ and $b_{1}^{*^{M \mid L}}=\min \left\{m_{1}+\kappa_{1}, \bar{c}\right\}$ do not depend on $b_{1}^{L}$. After simplifying the first-order condition, we obtain

$$
\begin{aligned}
\frac{\mathrm{d} \Pi_{1}}{\mathrm{~d} b_{1}^{L}}= & -\int_{\underline{c}}^{\bar{c}} f\left(b_{1}^{*^{L}}, m_{2}\right) \cdot\left(b_{1}^{*^{L}}-l_{1}\right) \mathrm{d} m_{2}+\int_{b_{1}^{* M \mid L}}^{\bar{c}} f\left(b_{1}^{*^{L}}, m_{2}\right) \cdot \kappa_{1} \mathrm{~d} m_{2} \\
& +\int_{b_{1}^{* M \mid \bar{L}}}^{b_{1}^{* M \mid L}} f\left(b_{1}^{*^{L}}, m_{2}\right) \cdot\left(m_{2}-m_{1}\right) \mathrm{d} m_{2} \stackrel{!}{=} 0 .
\end{aligned}
$$

The first-order condition can be rewritten using independence of project completion costs across any firm, $f(l, m)=\varphi(l) \cdot \varphi(m)$, and substituting for $b_{1}^{*^{M \mid \bar{L}}}$ and $b_{1}^{*^{M \mid L}}$ as

$$
b_{1}^{*^{L}}-l_{1}=\int_{\min \left\{m_{1}+\kappa_{1}, \bar{c}\right\}}^{\bar{c}} \varphi\left(m_{2}\right) \cdot \kappa_{1} \mathrm{~d} m_{2}+\int_{m_{1}}^{\min \left\{m_{1}+\kappa_{1}, \bar{c}\right\}} \varphi\left(m_{2}\right) \cdot\left(m_{2}-m_{1}\right) \mathrm{d} m_{2} .
$$

The right-hand side of Eq. (16) is a strictly positive constant so that there is a unique solution. To see that $b_{1}^{*^{L}}$ is the unique global maximizer, rewrite derivative (15) under the independence assumption as follows

$$
\frac{\mathrm{d} \Pi_{1}}{\mathrm{~d} b_{1}^{L}}=-\varphi\left(b_{1}^{L}\right)\left[\left(b_{1}^{L}-l_{1}\right)+\int_{b_{1}^{* M \mid L}}^{\bar{c}} \varphi\left(m_{2}\right) \cdot \kappa_{1} \mathrm{~d} m_{2}+\int_{b_{1}^{* M \mid \bar{L}}}^{b_{1}^{* M \mid L}} \varphi\left(m_{2}\right) \cdot\left(m_{2}-m_{1}\right) \mathrm{d} m_{2}\right] .
$$

We have $\varphi\left(b_{1}^{L}\right)>0$ for any $b_{1}^{L} \in[\underline{c}, \bar{c}]$ so that it does not affect the sign of the derivative. It is easy to see that the derivative vanishes at $b_{1}^{*^{L}}$. Evidently, the derivative is strictly positive if $b_{1}^{L}<b_{1}^{*^{L}}$ and strictly negative if $b_{1}^{L}>b_{1}^{*^{L}}$. It follows that $b_{1}^{*^{L}}$ is optimal unless it exceeds reserve price $\bar{c}$. In this case, the largest feasible bid $\bar{c}$ is the constrained optimizer. 


\subsection{Proof of Proposition 8 (entry indifference curve)}

Proof The equilibrium bidding function $\beta_{1}^{L}\left(l_{1}, m_{1}, \kappa_{1}\right)$ is continuous and monotonic increasing in $l_{1}$. Hence, for a given project cost $m_{1}$ (and a given capacity cost $\kappa_{1}$ ), the critical cost value for project $L$ where entry behavior changes from participating in auction $L$ with a bid smaller than $\bar{c}$ to participating in auction $L$ with maximum bid $\bar{c}$ (or skipping auction $L$ ) is given by the smallest value of project cost $l_{1}$ that implies maximum bid $\bar{c}$. Therefore, each critical value of the entry separatrix $l_{1}^{\text {crit }}$ solves

$$
l_{1}^{\text {crit }}+\omega_{1}^{L}\left(m_{1}, \kappa_{1}\right)=\bar{c}
$$

By definition of the entry separatrix $l_{1}^{\text {crit }}=g_{1}\left(m_{1}\right)$, we obtain

$$
g_{1}\left(m_{1}\right)=\bar{c}-\omega_{1}^{L}\left(m_{1}, \kappa_{1}\right) .
$$

(a) Property $\underline{c}<g_{1}\left(m_{1}\right)$ follows from the definition of $g_{1}(\cdot)$ and the fact that mark-up $\omega_{1}^{L}(\cdot)$ is strictly smaller than $\bar{c}-\underline{c}$ : due to $m_{2}-m_{1}<\bar{c}-\underline{c}$ if $m_{2}<\bar{c}$ and $m_{2}-m_{1} \leq \bar{c}-\underline{c}$ if $m_{2}=\bar{c}$ and by definition $\kappa_{1}<\bar{c}-\underline{c}, \omega_{1}^{L}(\cdot)<\bar{c}-\underline{c}$ implying $g_{1}\left(m_{1}\right)=\bar{c}-\omega_{1}^{L}(\cdot)>\underline{c}$. Since the mark-up $\omega_{1}(\cdot)$ is strictly positive if $m_{1}<\bar{c}$, we have $g_{1}\left(m_{1}\right)=\bar{c}-\omega_{1}^{L}(\cdot)<\bar{c}$ if $m_{1}<\bar{c}$. For $m_{1}=\bar{c}$, mark-up $\omega_{1}^{L}(\cdot)$ vanishes implying $g_{1}(\bar{c})=\bar{c}$.

(b) Differentiating $g_{1}\left(m_{1}\right)$ yields

$$
g_{1}^{\prime}\left(m_{1}\right)=-\frac{\partial \omega_{1}^{L}\left(m_{1}, \kappa_{1}\right)}{\partial m_{1}}= \begin{cases}\int_{m_{1}}^{m_{1}+\kappa_{1}} \varphi\left(m_{2}\right) \mathrm{d} m_{2}, & \text { if } m_{1}+\kappa_{1} \leq \bar{c}, \\ \int_{m_{1}}^{\bar{c}} \varphi\left(m_{2}\right) \mathrm{d} m_{2}, & \text { otherwise. }\end{cases}
$$

By strictly positive density $\varphi(\cdot)$, we obtain $g_{1}^{\prime}\left(m_{1}\right)>0$.

(c) Differentiating derivative $g_{1}^{\prime}\left(m_{1}\right)$ yields

$$
g_{1}^{\prime \prime}\left(m_{1}\right)= \begin{cases}\varphi\left(m_{1}+\kappa_{1}\right)-\varphi\left(m_{1}\right), & \text { if } m_{1}+\kappa_{1} \leq \bar{c} \\ -\varphi\left(m_{1}\right), & \text { otherwise }\end{cases}
$$

Open Access This article is distributed under the terms of the Creative Commons Attribution Noncommercial License which permits any noncommercial use, distribution, and reproduction in any medium, provided the original author(s) and source are credited.

\section{References}

Arozamena, L., Estelle, C.: Investment incentives in procurement auctions. Rev Econ Stud 71, 1-18 (2006) Ashenfelter, O.: How auctions work for wine and art. J Econ Perspect 3, 23-33 (1989)

Bernhardt, D., Scoones, D.: A note on sequential auctions. Am Econ Rev 84, 653-657 (1994)

Black, J., De Meza, D.: Systematic price differences between successive auctions are no anomaly. J Econ Manag Strategy 1, 607-628 (1992) 
Blume, A., Heidhues, P.: All equilibria of the Vickrey auction. J Econ Theory 114, 170-177 (2004)

Branco, F.: Sequential auctions with synergies: an example. Econ Lett 54, 159-163 (1997)

Brosig, J., Reiß, J.P.: Entry decisions and bidding behavior in sequential first-price procurement auctions: an experimental study. Games Econ Behav 58, 50-74 (2007)

Caillaud, B., Mezetti, C.: Equilibrium reserve prices in sequential ascending auctions. J Econ Theory 117, 78-95 (2004)

Celentani, M., Ganuza, J.J.: Corruption and competition in procurement. Eur Econ Rev 46, 1273-1303 (2002)

Che, Y.-K., Gale, I.: Standard auctions with financially constrained bidders. Rev Econ Stud 65, 1-29 (1998)

Cohen, S.E., Loeb, M.: Implicit cost allocation and bidding for contracts. Manag Sci 36, 1133-1138 (1990)

Dasgupta, S., Spulber, D.F.: Managing procurement auctions. Info Econ Pol 4, 5-29 (1989)

De Silva, D., Dunne, T., Kosmopoulou, G.: Sequential bidding in auctions of construction contracts. Econ Lett 76, 239-244 (2002)

De Silva, D., Dunne, T., Kosmopoulou, G.: An empirical analysis of entrant and incumbent bidding in road construction auctions. J Ind Econ 51, 295-316 (2003)

Deltas, G., Kosmopoulou, G.: 'Catalogue' vs. 'Order-of-Sale' effects in sequential auctions: theory and evidence from a rare book sale. Econ J 114, 28-54 (2004)

Elmaghraby, W.: The importance of ordering in sequential auctions. Manag Sci 49, 673-682 (2003)

Engelbrecht-Wiggans, R.: Sequential auctions of stochastically equivalent objects. Econ Lett 44, 87-90 (1994)

Gale, I.L., Hausch, D.B.: Bottom-fishing and declining prices in sequential auctions. Games Econ Behav 7, 318-331 (1994)

Gale, I.L., Hausch, D.B., Stegeman, M.: Sequential procurement with subcontracting. Int Econ Rev 41, 989-1020 (2000)

Holt, C.A.: Competitive bidding for contracts under alternative auction procedures. J Polit Econ 88, 433-445 (1980)

Jeitschko, T.D.: Equilibrium price paths in sequential auctions with stochastic supply. Econ Lett 64, 67-72 (1999)

Jofre-Bonet, M., Pesendorfer, M.: Bidding behavior in a repeated procurement auction. Eur Econ Rev 44, 1006-1020 (2000)

Jofre-Bonet, M., Pesendorfer, M.: Estimation of a dynamic auction game. Econometrica 71, 1443-1489 (2003)

Katzman, B.: A two-stage sequential auction with multi-unit demands. J Econ Theory 86, 77-99 (1999)

Luton, R., McAfee, R.P.: Sequential procurement auctions. J Public Econ 31, 181-195 (1986)

Maskin, E., Riley, J.: Optimal multi-unit auctions. In: Hahn, F. (ed.) The Economics of Missing Markets, Information and Games, pp. 312-355. Oxford: Clarendon Press (1989)

Maskin, E., Riley, J.: Asymmetric auctions. Rev Econ Stud 67, 413-438 (2000)

McAfee, R.P., McMillan, J.: Auctions and bidding. J Econ Lit 25, 699-738 (1987a)

McAfee, R.P., McMillan, J.: Competition for agency contracts. Rand J Econ 18, 296-307 (1987b)

McAfee, R.P., Vincent, D.: The declining price anomaly. J Econ Theory 60, 191-212 (1993)

Menezes, F.M., Monteiro, P.K.: Synergies and price trends in sequential auctions. Rev Econ Des 8, 85-98 (2003)

Milgrom, P.R.: Auctions and bidding: a primer. J Econ Perspect 3, 3-22 (1989)

Myerson, R.B.: Optimal auction design. Math Oper Res 6, 58-73 (1981)

Plum, M.: Characterization and computation of Nash-equilibria for auctions with incomplete information. Int J Game Theory 20, 393-418 (1992)

Porter, R.H., Zona, J.D.: Detection of bid rigging in procurement auctions. J Polit Econ 101, 518-538 (1993)

Reiß, J.P., Schöndube, J.R.: First-price equilibrium and revenue equivalence in a sequential procurement auction model. METEOR Research Memorandum No. 07-003. Maastricht University (2007)

Riley, J.G., Samuelson, W.F.: Optimal auctions. Am Econ Rev 71, 381-392 (1981)

Riordan, M.H., Sappington, D.: Awarding monopoly franchises. Am Econ Rev 77, 375-387 (1987)

Vickrey, W.: Counterspeculation, auctions, and competitive sealed tenders. J Finance 16, 8-37 (1961)

Von der Fehr, N.-H.M.: Predatory bidding in sequential auctions. Oxford Econ Pap 46, 345-356 (1994)

Von der Fehr, N.-H.M., Riis, C.: Option Values in Sequential Markets. Working Paper. Oslo: University of Oslo (1998) 
Weber, R.J.: Multiple object auctions. In: Engelbrecht-Wiggans, R., Shubik, M., Stark, R. (eds.) Auctions, Bidding and Contracting: Uses and Theory, pp. 165-191. New York: New York University Press (1983)

Zeithammer, R.: Sequential auctions with information about future goods. Working Paper (2006)

Zeithammer, R.: Strategic bid-shading and sequential auctioning with learning from past prices. Manag Sci 53, 1510-1519 (2007) 